\title{
Benchmark Experimental Database for Multiphase Combustion Model Input and Validation: Baseline Case
}

\section{PROGRESS REPORT}

\section{John F. Widmann S. Rao Charagundla Cary Presser}

Process Measurements Division

Chemical Science and Technology Laboratory

\section{Alan Heckert}

Statistical Engineering Division Information Technology Laboratory U.S. Department of Commerce National Institute of Standards and Technology

Gaithersburg, Maryland 20899 


\section{Characterization of a Residential Fire Sprinkler Using Phase Doppler Interferometry}

\section{John F. Widmann}

U.S. DEPARTMENT OF COMMERCE

Technology Administration

Fire Safety Engineering Division

Building and Fire Research Laboratory

National Institute of Standards

and Technology

Gaithersburg, MD 20899

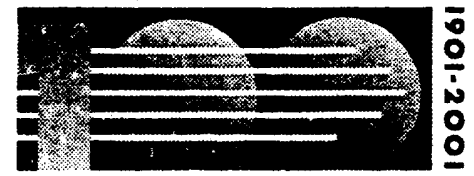

NIST CENTENNIAL.

\section{NIST}

National Institute of Standards and Technology

Technology Administration

U.S. Department of Commerce 


\section{CONTENTS}

\section{page}

$\begin{array}{ll}\text { Abstract } & 1\end{array}$

1. Introduction 2

2. Description of Experimental Facility 3

2.1. Spray Combustion Reactor - Baseline Case 3

2.2. Phase Doppler Interferometer 4

2.3. Fourier Transform Infrared Spectrometer 7

3. Results of Experiments 7

3.1. Operating and Boundary Conditions 7

$\begin{array}{ll}\text { 3.2. } & \text { Fuel Spray Measurements } \\ & 8\end{array}$

3.3. Exhaust Chemical Species Measurements 15

4. summary 16

$\begin{array}{ll}\text { 5. } & \text { References } \\ \end{array}$ 


\section{IIST OF TABLES}

page

Table 1. Operating conditions for the baseline case. 20

Table 2. Uncertainty budget for the location of the PDI probe volume. 21

Table 3. uncertainty budget for the fuel flow rate $\left(3.0 \mathrm{~kg} \mathrm{~h}^{-1}\right)$.

22

Table 4. Uncertainty budget for the combustion air flow rate

23 $\left(56.7 \mathrm{~m}^{3} \mathrm{~h}^{-1}\right)$.

Table 5. The locations and mean values of the wall temperatures.

24

Table 6. The locations and mean values of the exit gas temperatures.

25

Table 7. Uncertainty budget for the wall and gas temperatures measurements.

Table 8. ASCII data file format.

Table 9. Uncertainty budget for the phase Doppler interferometry measurements.

Table 10. Uncertainty budget for the species concentration measurements. 


\section{LIST OF FIGURES}

page

Figure 1. Schematic of (A) the reference spray combustion facility and $(B)$ the nozzle used to generate the fuel spray.

Figure 2. Relevant dimensions of the reactor and the burner.

Figure 3. Schematic of the image observed through the viewing . port of the PDI receiving optics when the probe volume is located at (A) $\mathbf{x}=\mathrm{y}=0$ and $\mathbf{z}=1 \mathrm{~mm}$, and (B) $\mathbf{x}=y=0$ and $\mathrm{z}=3 \mathrm{~mm}$.

Figure 4. Droplet size distributions at $\mathbf{z}=5 \mathrm{~mm}$ and $\mathrm{r}=2.76 \mathrm{~mm}$ obtained with the PDI. Presented are (A) the raw data from 13 experiments, (B) the raw data with the distribution obtained fiom a cubic spline, and (C) the cubic spline with the $95 \%$ pseudo-confidence bands.

Figure 5. Droplet size distribations at various radial coordinates $5 \mathrm{~mm}$ downstream of the nozzle.

Figure 6. Droplet size distributions at various radial coordinates $15 \mathrm{~mm}$ downstream of the nozzle.

Figure 7. Droplet size distributions at various radial coordinates $25 \mathrm{~mm}$ downstream of the nozzle.

Figure 8. Droplet size distributions at various radial coordinates $35 \mathrm{~mm}$ downstream of the nozzle.

Figure 9. Droplet size distributions at various radial coordinates $45 \mathrm{~mm}$ downstream of the nozzle. 
Figure 10. Droplet size distributions at various radial coordinates $55 \mathrm{~mm}$ downstream of the nozzle.

Figure 11. Droplet size distributions at various radial coordinates $65 \mathrm{~mm}$ downstream of the nozzle.

Figure 12. Droplet axial velocity distributions at various radial coordinates $5 \mathrm{~mm}$ downstream of the nozzle.

Figure 13. Droplet axial velocity distributions at varipus radial coordinates $15 \mathrm{~mm}$ downstream of the nozzle.

Figure 14. Droplet axial velocity distributions at various radial coordinates $25 \mathrm{~mm}$ downstream of the nozzle.

Figure 15. Droplet axial velocity distributions at various radial coordinates $35 \mathrm{~mm}$ downstream of the nozzle.

Figure 16. Droplet axial velocity distributions at various radial coordinates $45 \mathrm{~mm}$ downstream of the nozzle.

Figure 17. Droplet axial velocity distributions at various radial coordinates $55 \mathrm{~mm}$ downstream of the nozzle.

Figure 18. Droplet axial velocity distributions at various radial coordinates $65 \mathrm{~mm}$ downstream of the nozzle.

Figure 19. Droplet radial velocity distributions at various radial coordinates $5 \mathrm{~mm}$ downstream of the nozzle.

Figure 20. Droplet radial velocity distributions at various radial coordinates $15 \mathrm{~mm}$ downstream of the nozzle.

Figure 21 . Droplet radial velocity distributions at various radial coordinates $25 \mathrm{~mm}$ downstream of the nozzle. 
Figure 22. Droplet radial velocity distributions at various radial coordinates $35 \mathrm{~mm}$ downstream of the nozzle.

Figure 23. Droplet radial velocity distributions at various radial 52 coordinates $45 \mathrm{~mm}$ downstream of the nozzle.

Figure 24. Droplet radial velocity distributions at various radial coordinates $55 \mathrm{~mm}$ downstream of the nozzle.

Figure 25. Droplet radial velocity distributions at various radial coordinates $65 \mathrm{~mm}$ downstream of the nozzle.

Figure 26. Sauter mean diameter, $D_{32}$, at seven axial locations downstream of the nozzle $(\mathbf{z}=5,15,25,35,45,55$, and $65 \mathrm{~mm})$.

Figure 27. Droplet axial velocity, $v_{z}$, at seven axial locations downstream of the nozzle $(\mathbf{z}=5,15,25,35,45,55$, and $65 \mathrm{~mm})$.

Figure 28. Droplet radial velocity, $\mathrm{v}_{\mathrm{r}}$, at seven axial locations downstream of the nozzle $(z=5,15,25,35,45,55$, and $65 \mathrm{~mm})$.

Figure 29. Droplet number density at seven axial locations downstream of the nozzle $(z=5,15,25,35,45,55$, and $65 \mathrm{~mm})$.

Figure 30. Droplet volume flux at seven axial locations downstream of the nozzle $(\mathbf{z}=5,15,25,35,45,55$, and $65 \mathrm{~mm})$.

Figure 31. A comparison of reported number density at three locations in the spray with one and two components of velocity measured.

Figure 32. A comparison of reported size distributions with and without the radial component of velocity measured at (A) $z=5 \mathrm{~mm}$ and (B) $z=25 \mathrm{~mm}$. 
Figure 33. Raw data obtained with the PDI showing the number of fringes crossed for each measurement direction (axial and radial).

Figure 34. The calculated probe area based upon the number of fringes that individual droplets cross.

Figure 35. The normalized mass flow rate of fuel at various downstream locations. Values from literature are shown for comparison.

Figure 36. Number and mass distributions measured with the FDI illustrating the difficulty of measuring number and mass distributions simultaneously.

Figure 37. The exit concentrations of various species in the reactor.

Figure 38. Theoretical species concentrations in the reactor emissions. 


\title{
Benchmark Experimental Database for Multiphase Combustion Model Input and Validation: Baseline Case

\author{
John F. Widmann, S. Rao Charagundla, Cary Presser \\ Chemical Science and Technology Laboratory \\ National Institute of Standards and Technology \\ Gaithersburg, MD USA 20899
}

\author{
Alan Heckert \\ Information Technology Laboratory \\ National Institute of Standards and Technology \\ Gaithersburg, MD USA 20899
}

\begin{abstract}
Experimental data were collected for the purpose of validating multiphase combustion models and submodels. A spray combustor was fabricated that permits well-defined boundary and input conditions, and measurements were carried out that characterize the fuel spray, wall temperatures, gas temperatures and species concentrations at the reactor exhaust. The operating conditions for the baseline case were defined by NIST personnel and industrial collaborators involved in model development. A methanol spray, generated with a pressure-jet nozzle, was studied with phase Doppler interferometry to measure the size, velocity, number density, and mass flux of the fuel droplets. Fourier transform infrared spectroscopy was used to measure the species concentrations in the reactor emissions. The conversion of methanol in the reactor was found to be $\sim 80 \%$. Inlet and outlet air velocity (including inlet air swirl intensity) and heat flux measurements at the reactor wall are planned. Flow field velocity and temperature measurements are also planned to complete the baseline database.
\end{abstract}

Key words: CFD model validation, mdtiphase combustion, spray combustion, phase Doppler interferometry, FTIR spectroscopy

Certain commercial equipment, materials, or software are identified in this publication to specify adequately the experimental procedure. Such identification does not imply recommendation or endorsement by the National institute of Standards and Technology, nor does it imply that the materials or equipment are necessarily the best available for this purpose. 


\section{Introduction}

Control of process efficiency and the formation of species byproducts fiom industrial thermal oxidation systems (e.g., power generation and treatment of liquid chemical wastes), is generally based on apriori knowledge of the input stream physical and chemical properties, desired stoichiometric conditions, and monitoring of a few major chemical species in the exhaust. Optimization of the performance of these systems is relying increasingly on computational models and simulations that help provide relevant process information in a cost-effective manner. In general, there is a dearth of reliable data for specifying model initial/boundary conditions, and a need for validation of the numerical codes. System performance is dependent on the liquid atomization, chemistry, aerodynamic design, and the degree of liquid/air mixing within the reactor. Provision of in-situ, real-time data on the characteristics of the droplet field and flame structure, and an understanding of its interrelationship with the system operating conditions, heat transfer, and particulate and gaseous byproducts, is crucial for the development and validation of advanced computational models, diagnostics, and instrumentation.

Although computational fluid dynamics (CFD) offers a cost-effective alternative to experiments, the accuracy of the CFD model must first be assured. This should be accomplished in two ways: verification and validation (Oberkampf et al., 1997). Verification involves ensuring that the algebraic and differential equations within the model have been accurately solved. In addition to verifying that the numerical code arrives at the correct solution, it is also necessary to determine if the correct model has been solved. This is the validation step. The objective of this report is to provide experimental data for the purpose of CFD model and submodel validation, and interested parties are encouraged to use the enclosed benchmark spray combustion data set. A file (mesh.txt) in PLOT3D format* is provided in the accompanying diskettes that may be used to assist in initiation of the simulation of the NIST Reference Spray Combustion Facility.

This report presents data obtained fiom a baseline spray flame within the reference spray combustion facility at NIST. Methanol was chosen as the fuel for the baseline case because the thermodynamic and kinetic data necessary to model the gas phase

\footnotetext{
- The file contains a sample 2-D structured mesh of the numerical simulation of the NIST facility. The first row in file is the number of domains, and the second row is the number of cells in $x, y$, and $z$ dimensional planes for each domain. The actual mesh coordinates for $x, y$, and $z$ follow in sequential order across the four columns. The single digit numbers at the end of the file detail whether or not the mesh node is blocked. (Courtesy of CFD Research Corporation,Huntsville, $A L$.)
} 
combustion are readily available (Afeefy $\boldsymbol{e t}$ al., 1998; also available on the World Wide Web at http://webbooknist.gov/). The spray data presented were collected nonintrusively using phase Doppler interferometry (PDI). Data are presented for the size and velocity distributions of the fuel droplets, the droplet number density, and the volume flux of fuel droplets within the spray. The enclosed combustion chamber provides well-characterized boundary conditions, and wall temperature data are provided as a function of axial position. Temperature and species measurements obtained at the reactor exit are provided, which can be used for boundary conditions or validation of computational results. Gas-phase velocity measurements are planned using PDI by seeding the combustion air with spherical salt particles with diameters of order one micrometer, and these results will be compared to measurements obtained with a pitot tube. Heat flux measurements at several elevations along the reactor wall are also planned.

\section{Description of Experimental Facility and Procedure}

\section{I. Spray Combustion Reactor - Baseline Case}

The experiments were conducted in a stainless steel, enclosed spray combustion facility, shown in Fig. 1A. The experimental facility includes a swirl burner with a movable 12-vane swirl cascade. The cascade is adjusted to impart the desired degree of swirl intensity to the combustion air stream that passes through a $0.10 \mathrm{~m}$ diameter passage and coflows around the fuel nozzle. The swirl intensity is a measure of the angular momentum of the combustion air. It is characterized by the swirl number, S, defined as the ratio of the axial flux of angular momentum to the axial flux of linear momentum (Gupta $\boldsymbol{e t}$ al., 1984). The vane angle and combustion air flow rate were $50^{\circ} \pm 1^{\circ}$ and $56.7 \pm 1.7 \mathrm{~m}^{3} \mathrm{~h}^{-1}$, respectively. Using the correlation suggested by Beér and Chigier (1972), the experimental conditions used here should result in a swirl number of $S=0.48$, which is a swirling flow of moderate intensity. However, recent CFD modeling of the vane cascade and combustion air passage yields a swirl number of $\mathrm{S}=0.54$. Because flame stability and the combustion process are strongly dependent on the amount of swirl present, experimental measurements are in progress to investigate the discrepancy between the above estimates.

Figure 1B presents a close-up view of the burner and nozzle. The liquid fuel is forced through a pressure-jet nozzle and forms a hollow-cone spray with a nominal $60^{\circ}$ full cone angle. A parallel program is underway to develop a reference atomizer with well-defined droplet size and velocity distributions. The atomizer will then provide 
known spray characteristics at the inlet, and define this boundary condition for CFD models. This atomizer is planned to be available in the next phase of this program. Methanol was used for these experiments, and the flow rate was maintained at $3.0 \pm$ $0.02 \mathrm{~kg} \mathrm{~h}^{-1}$. The fuel and combustion air were introduced into the reactor at room temperature. The fuel flow rate, combustion air flow rate, wall temperatures, and exiting gas temperatures were monitored and stored using LabVIEW data acquisition software running on a $166 \mathrm{MHz}$ personal computer. The operating conditions for the baseline case are summarized in Table 1.

The burner is enclosed within a stainless steel chamber to provide improved reproducibility and control of the spray flame. The chamber height is $1.2 \mathrm{~m}$ and the inner diameter is $0.8 \mathrm{~m}$. Several windows provide optical access, and a stepper-motordriven traversing system translates the entire burner/chamber assembly permitting measurements of spray properties at selected locations downstream of the nozzle. Additional details on the design of the burner are available in the literature (Presser $\boldsymbol{e t}$ $a l .$, 1993). The relevant dimensions necessary for modeling the facility are presented in Fig. 2. Note that the reactor exit is off-axis, which makes the problem nonaxisymmetric.

\subsection{Phase Doppler Interferometer}

Since its introduction (Bachalo and Houser, 1984a; Bachalo and Houser, 1984b), phase Doppler interferometry (PDI) has been used to characterize sprays in areas such as liquid fuel spray combustion, coal slurry combustion, coatings, pesticides, fire suppression, and others. PDI is an extension of laser Doppler velocimetry that measures droplet size as well as velocity. Phase Doppler techniques involve creating an interference pattern in the region where two laser beams intersect and results in a region consisting of alternating light and dark fringes. The region where the laser beams intersect is called the probe volume or sample volume. Due to the interference pattern, a droplet passing through the probe volume scatters light that exhibits an angular intensity distribution which is characteristic of the size, refractive index, and velocity of the droplet. For a droplet with known refractive index, the size and velocity can be determined by analyzing the scattered light collected with several photomultiplier tubes.

The PDI is a single-point (or spatially resolved) diagnostic instrument in that it obtains information about the spray at a single point in space. Only by moving the probe volume (or, equivalently, the spray) can one map out the spatial distribution of 
the spray characteristics. The PDI is also a single particle instrument in that information is obtained for only one droplet at a time. This offers advantages over integrating techniques because the characteristics of a particular droplet (size, velocity, etc.) can be recorded and the data can be separated into classes (size classes, velocity classes) to further characterize the spray system.

The spray measurements reported here were made using a two-component Phase Doppler Particle Analyzer from Aerometrics to measure the droplet size and velocity distributions and the spray intensity. The instrument is composed of the following components: (i) transmitter (model XMT-1100-4S), (ii) motor controller (model MCB7100-1), (iii) receiver (model RCV-2100), (iv) counter-type signal processor (model PDP-3100), and (v) data management system (model DMS-4000-5). The PDI was controlled using Aerometrics PDPA software version 4.275 run on a $66 \mathrm{MHz}$ personal computer. The receiving optics were aligned at a $30^{\circ}$ scattering angle measured from the direction of propagation of the laser beams, and the transmitting and receiving optics were aligned at the same elevation. A $5 \mathrm{~W}$ Spectra Physics argon ion laser operating in multi-line mode was used as the illumination source. The blue (wavelength $=488 \mathrm{~nm}$ ) and green (wavelength $=514.5 \mathrm{~nm}$ ) lines of the argon ion laser were separated and focussed by the transmitting optics to intersect and form the probe volume. Additional details of the optical arrangement are available elsewhere (Presser et al., 1994).

The location of the reaction chamber is controlled by a series of stepper motors that permit the reactor to be moved in three directions. For the experiments described in this report, the position of the reactor was varied in only two directions, which enabled the spray to be probed in the axial and radial directions. The reactor was not moved in the direction of propagation of the PDI laser beams. The third dimension is usually used for alignment of the optics, but could be used to determine the tangential component of velocity if necessary. Table 2 presents the uncertainties associated with determining the location of the PDI probe volume (i.e. the location where the beams intersect) relative to the spray nozzle. The uncertainty in the axial ( $\mathbf{A z}$ )position, which is a quantitative estimate of the maximum that this measurement could be in error, is primarily due to the difficulty in aligning the laser beams with the surface (face) of the nozzle $(\mathrm{z}=0)$. Uncertainties in the two horizontal positions $(\boldsymbol{A} \boldsymbol{x}$ and $A y)$ result from the difficulty in locating the probe volume exactly above the nozzle. The uncertainty in the spray angle, $\Delta \theta$, results from an estimate of the maximum that the burner/nozzle assembly deviates from the vertical position. This uncertainty, $\Delta \theta$, also depends on if 
the orifice is designed and fabricated properly so that the spray exits vertically. This deviation results in a negligible error in the measurements close to the node, but can become significant further downstream as shown in the expression for $\Delta r$ in Table 2.

To characterize the droplets as a function of location within the spray, it is first necessary to establish the origin of the coordinate system. This was done using the following procedure: (i) align the PDI receiving optics with the probe volume located in a downstream region of the spray where the number density of droplets is high and the light scattering is intense, (ii) align the surface of the nozzle with the PDI probe volume ( $z$ coordinate), (iii) adjust the horizontal position perpendicular to the direction of propagation of the PDI laser beams ( $x$ coordinate), and (iv) adjust the horizontal position in the direction of propagation of the laser beams (y coordinate) so that the PDI probe volume corresponds with the center of the spray nozzle. This alignment procedure is carried out visually.

The alignment of the PDI receiving optics was performed as described in the operating manual, and the details will not be repeated (Aerometrics Inc., 1987). After the axial coordinate was adjusted (step (ii) in the alignment procedure), the burner was lowered slightly $(-1 \mathrm{~mm})$ so that the probe volume was located just downstream of the nozzle. The burner was then translated in the $\mathrm{x}$-direction until the probe volume directly above the nozzle face. Adjustment in this direction (x coordinate) was more straightforward than in the other horizontal direction (y coordinate) because one can look down vertically at the crossing laser beams to facilitate the alignment. In the ydirection, the probe volume is elongated due to the small intersection angle of the laser beams, and this increased the difficulty in aligning the probe volume in this direction. Therefore, the alignment in the y-direction was accomplished utilizing the viewing port in the PDI receiving optics, as shown in Fig. 3. Figure 3A depicts the image that appears in the viewing port when the probe volume is located $1 \mathrm{~mm}$ above the nozzle $(\mathrm{z}$ $=1 \mathrm{~mm}$ ). The horizontal lines correspond to the intersecting laser beams, and the vertical lines represent the $100 \mu \mathrm{m}$ slit that limits the amount of light detected by the photomultiplier tubes. Because of the very high intensity of the elastic scattering at this location, the spray above the probe volume is illuminated sufficiently to be observed through the viewing port. The cone formed by the spray can be used to align the probe volume in the y-direction. If the burner is lowered so that the probe volume is further downstream, the image appears like that shown in Fig. 3B, which corresponds to $z=3$ $\mathrm{mm}$. 


\subsection{Fourier Transform Infrared Spectrometer}

Gas-phase species concentrations were measured using Fourier transform infrared (FTIR) spectroscopy. An FTIR spectrometer(BioRad FTS-40) equipped with a DTGS detector was used for extractive sampling of chemical species in the combustor emissions. A gas sampling system, consisting of an air-cooled sampling probe, a heated gas line, and a vacuum pump, facilitated the transport of the sample gas extracted fiom the spray combustor into the single pass gas cell in a continuous manner. The sampling probe was designed to aerodynamically quench chemical reactions occurring within the gasses being sampled. The sampling gas line was also provided with a means for purging.

In this investigation, the FTIR spectrometer was operated with $2 \mathrm{~cm}^{-1}$ resolution. The gas cell, equipped with $\mathrm{KBr}$ windows, was unheated and had a $0.1 \mathrm{~m}$ path length. The sample gas enters the cell at one end and continuously exits at the other end. The pressure inside the cell was kept steady at a constant sub-atmospheric level. During operation, the sampling gas line was purged frequently with a stream of purified air. The data acquisition and analysis functions were accomplished with the software provided by the instrument vendor. In each test nun, care was taken to allow sufficient time for equilibrating the flow and thereby assuring a steady state flow condition. Generally, three to five spectra were obtained at each probe location. Once the data acquisition at one location was completed the probe was removed and transferred to an adjacent location.

In each experiment, the gas-sampling probe was inserted into the exhaust gas stream in such a way to assure probing the conditions at the selected exit plane, about $0.533 \mathrm{~m}$ fiom the end plate and $0.508 \mathrm{~m}$ from the vertical axis of the combustion chamber (see Fig. 1). The extracted gas samples were analyzed with the FTIR spectrometer and the spectral data were recorded. These spectra were used to identify the species present in the reactor emissions. Separately generated calibration spectra of each identified species was then used to quantify the species in the gas sample.

\section{Results of Experiments}

\section{I. Operating and Boundary Conditions}

The fuel flow rate into the reactor was maintained at $3.0 \pm 0.02 \mathrm{~kg} \mathrm{~h}^{-1}$, and Table 3 summarizes the estimated uncertainties in the measurement. The methanol flow rate was measured using a COX turbine meter. The rotation frequency of the turbine meter was calibrated as a function of methanol flow rate, and the analog voltage signal from 
the turbine meter was read into the computer used for data acquisition and calibrated as a function of the turbine frequency. Both of the uncertainties associated with these calibrations are presented in the table. Combining the calibration uncertainties with the standard deviation obtained from repeated observations yields a combined standard uncertainty of $0.0157 \mathrm{~kg} \mathrm{~h}^{-1}$.

The combustion air was delivered through the swirl burner at a rate of $56.7 \pm 1.7 \mathrm{~m}^{3}$ $\mathrm{h}^{-1}$. The flow rate was measured using a $6.35 \mathrm{~mm}$ i.d. COX sonic nozzle for which the manufacturer reports a $3 \%$ uncertainty. This uncertainty is significantly larger than those associated with the calibration of the pressure transducer, the uncertainty of the pressure gauge, or the random errors determined from repeated observations. Table 4 summarizes the various components of the combined uncertainty, which is equal to $1.73 \mathrm{~m}^{3} \mathrm{~h}^{-1}$.

Thermocouples (K-type) were used to measure the wall temperature and the gas temperature at the exit of the reactor. The locations and mean temperatures are summarized in Tables 5 and 6 . The temperature of the exit gas was measured at the same locations where the species concentration data were obtained. The uncertainty budget for the temperature measurements is presented in Table 7, and the combined uncertainty is $3{ }^{\circ} \mathrm{C}$ and $5.5{ }^{\circ} \mathrm{C}$ for the wall and gas temperatures, respectively. Calibration of the sonic nozzle and thermocouples is planned prior to distribution of the final report for the baseline case.

\subsection{Fuel Spray Measurements}

Figure 4A presents an example of droplet size data obtained at one location in the spray $(z=5 \mathrm{~mm}, r=2.76 \mathrm{~mm})$. Size distributions (probability as a function of droplet diameter) fiom thirteen experiments are shown in the figure. The data show good agreement over the thirteen' experiments, with the largest variation in the probability density function occurring near a droplet diameter of $15 \mu \mathrm{m}$. The data fiom Fig. 4A are shown in Fig. 4B with a cubic spline interpolation, which represents the mean size distribution. Figure $4 \mathrm{C}$ presents the mean distribution obtained fiom the cubic spline interpolation with pseudo-confidence bands that represent an approximate $95 \%$ confidence interval. The pseudo-confidence bands were calculated as $\pm 2 s n^{-1 / 2}$, where $s$ is the standard deviation of the raw data and $n$ is the number of samples.

Experimental data were collected at seven elevations downstream of the nozzle $(\mathrm{z}=$ $5,15,25,35,45,55$, and $65 \mathrm{~mm}$ ). These data are presented in the following manner. Droplet size distributions corresponding to numerous radial locations at each 
downstream location (z-coordinate) are presented in Figs. 5 - 11; axial velocity distributions $\left(\mathrm{v}_{\mathrm{z}}\right)$ are presented in the same fashion in Figs. 12 - 18; and radial velocity distributions $\left(\mathrm{v}_{\mathrm{r}}\right)$ are presented in Figs. $19-25$. The figures present the cubic interpolation through the distributions. The pseudo-confidence (95\%) bands are also shown in the figures.

The data shown in Figs. 5 - 25 are provided on the disk accompanying this report. The figures provide a quick reference for selecting the data files of interest. The ASCII text files contain four columns of data. The four columns are the droplet diameter (or velocity), the cubic spline interpolation, the lower confidence band, and the upper confidence band, respectively. The file names correspond to the type of distribution and location in the spray. Files that begin with $\mathrm{D}, \mathrm{Z}$; and $\mathrm{R}$ correspond to size, axial velocity, and radial velocity distributions, respectively. The number immediately following the letter indicates the axial position downstream of the nozzle, and the following number indicates the radial coordinate. For example, the file D35_2159.spl contains the size distribution measured at $\mathrm{z}=35 \mathrm{~mm}$ and $\mathrm{r}=21.59 \mathrm{~mm}$. The radial coordinates are also indicated in Figs. 5 - 25.

Droplet Sauter mean diameters, $D_{32}$, are presented in Fig. 26 for each of the seven downstream locations. The mean axial and radial velocity componenets of the droplets are presented in Figs. 27 and 28, respectively. In addition, the mean components of the droplet velocities are summarized in the files axialvel.dat and radvel.dat contained on the accompanying diskettes. The files contain twenty-one columns that correspond to the radial coordinate, velocity, and uncertainty for each of the seven elevations shown in the figures.

Figure 29 presents droplet number densities measured with the PDI at the downstream locations corresponding to data shown'inFigs. 5 - 25. The volume flux of fuel droplets corresponding to the same locations is shown in Fig. 30. The number densities and volume fluxes are corrected for the instrument response time and rejected signals, which is discussed in detail elsewhere (Widmann et $\boldsymbol{a l} .$, 1999b). The horizontal error bars express the uncertainty in the radial coordinate, and the vertical error bars correspond to twice the standard error of the mean $\left(2 s n^{-1 / 2}\right)$. Note that systematic errors associated with the instrument are not included in the figures at this time but should be considered when comparing the data to numerical results. Systematic errors associated with PDI are discussed further below. The accompanying diskettes contain the data presented in Figs. 29 and 30 in ASCII format, and also contain the Sauter mean diameters. The seven files are named spray__.dat, spray_2.dat, etc., and correspond to 
different elevations downstream of the nozzle. The column format of the data files is summarized in Table 8.

The uncertainties associated with droplet number density and flux measurements deserve additional attention due to the difficulty in their quantification and their importance in satisfying mass conservation. Zhu et al. (1993) have discussed the difficulties of measuring number densities and fluxes using PDI. Simultaneously measuring the number density and volume flux is particularly difficult because the number density is dominated by the many small droplets while the volume flux is strongly dependent on the larger droplets. Therefore, if the size range of the droplets in the spray is greater than the dynamic range of the instrument (35:1 for the counter based processors, as used in this study), the simultaneous measurement of number density and volume flux is very challenging. Research into statistical methods of accurately accounting for the droplets beyond the measurable size range of the PDI is in progress and may lead to improved volume flux measurements.

The accuracy of both number density and volume flux measurements depends on several factors (e.g., the dynamic range of the instrument and accurately determining the probe volume). There are three main factors that contribute to uncertainties in the probe volume. The first is the variation of the probe diameter with droplet size, which results from the Gaussian intensity profile of the laser beam. The probe volume can be approximated as a cylinder, where the laser beams determine the diameter and the length is determined by the $100 \mu \mathrm{m}$ aperture in the receiving optics. The effective diameter of the laser beam depends on the droplet size because larger droplets scatter significantly more light than smaller droplets (van de Hulst, 1951). Smaller droplets must pass through the center of the probe volume where the laser light intensity is high while larger droplets can scatter sufficient light to be detected when passing through the wings of the Gaussian profile. Therefore, the probe volume is larger for the larger droplets than for the smaller ones.

The second factor contributing to the uncertainty in the probe volume is the error associated with measuring its length. The accuracy with which this dimension can be measured depends upon the resolution of the receiver optical system. Bachalo et al. (1988) estimated this uncertainty to be $15 \%$ for a $100 \mu \mathrm{m}$ slit; however, they note that larger particles will produce greater uncertainty in this dimension. The third factor that can contribute to the uncertainty in the probe volume is the particle trajectory. It is known that when the droplets have a component of velocity in the direction of the laser beams (the direction that is not measured), the probe volume determined by the PDI 
software will be in error. Unfortunately, the magnitude of this error is difficult to determine. For the spray investigated in this study, it has been reported that the droplets have a non-negligible tangential component of velocity near the nozzle, but this component is significantly reduced further downstream (Presser et al., 1993). This may result in errors in number density and flux measurements close to the nozzle, for example, $\mathrm{z}<20 \mathrm{~mm}$.

The difficulties associated with quantifying the measurement uncertainties is demonstrated in Fig. 31, where the reported number density is given at three locations within the spray. The data correspond to two instrument settings. In one case, the droplet size and two components of the velocity are measured, while in the other case, the size and only one component of the velocity are measured. The measurements made with only one component of velocity yielded number densities $5-7$ times as large as those made with two components of velocities. Note that there is no significant difference in the validation fraction between experimental runs with and without the radial velocity measurement. The validation fraction is the fraction of measured signals from which the processor was able to determine the size and velocity of the droplet, and in all of the experiments presented in Fig. 31 the validation fraction was $\sim 0.5$. Also, the area of the sample volume reported by the PDI software was the same for both settings; however, it will be shown below that this may be incorrect. Figures 32 - 34 reveal possible explanations for the discrepancy between the number density measurements. Figure $\mathbf{3 2}$ shows size distributions obtained with and without the radial velocity measurement. Turning off the second velocity component results in a measured size distribution that is shifted toward smaller droplets. It is possible that the inclusion of these smaller droplets in the size distribution is responsible for the substantial increase in the number density.

Figure $\mathbf{3 3}$ presents data corresponding to the number of fringes that each droplet crossed during an experimental run in which the size and two components of velocity were measured. The closed symbols correspond to measurements in the radial direction (green laser beams), and the open symbols correspond to measurements in the vertical direction (blue laser beams). Note that there are open symbols that are obscured by the closed symbols. It is clear from Fig. $\mathbf{3 3}$ that, in general, more blue fringes are crossed during the measurement than green fringes. This suggests that the probe area may be larger for the measurements in the axial direction than the radial direction. This would explain the discrepancy in Fig. $\mathbf{3 1}$ if the probe area determined from the blue laser 
beams were used in calculating number density and volume flux when both axial and radial velocity components are measured.

Figure 34 presents the calculated probe area for measurements with and without the radial velocity. The probe area was determined as a function of droplet size fiom the raw data shown in Fig. 33. The probe area, $A_{P}$, can be calculated from

$$
A_{p}\left(d_{p}\right)=D_{p}\left(d_{p}\right) w_{s l i t} / \sin (\theta)
$$

where $d_{p}$ is the droplet diameter, $D_{p}$ is the laser beam diameter, $w_{s l i t}$ is the slit width, and $\theta$ is the scattering angle. For these experiments, the slit width and scattering angle were $100 \mu \mathrm{m}$ and $30^{\circ}$, respectively. The laser beam diameter is computed from

$$
\mathrm{D}_{\mathrm{P}}\left(\mathrm{d}_{\mathrm{p}}\right)=\delta\left[\mathrm{N}_{\max }^{2}\left(\mathrm{~d}_{\mathrm{p}}\right)-\mathrm{N}_{\min }^{2}\left(\mathrm{~d}_{\mathrm{p}}\right)\right]^{1 / 2},
$$

where, 6 is the fringe spacing, which is determined by the wavelength of the laser light and the intersection angle of the laser beams. For this experimental configuration, the fringe spacing was $4.00 \mu \mathrm{m}$ and $3.95 \mu \mathrm{m}$ for the green and blue laser beams, respectively. The processor requires a minimum number of fringe crossings, $N_{\min }$, for a signal to be validated. Also, there will be a maximum number of fringe crossings, $N_{\max }$, in each size class due to the finite size of the laser beams. The PDI software records the number of fringe crossings for each droplet measured; therefore, $N_{\min }$ and $\mathrm{N}_{\max }$ can be computed for each size class and Eq. (2) can be used to compute $\mathrm{D}_{\mathrm{P}}$ as a function of droplet size. Figure 34 reveals that the probe area is different for the two channels, which suggests that the discrepancy shown in Fig. 31 may be due in part to the PDI using a probe area that is calculated incorrectly for one of the channels.

To evaluate the accuracy of the volume flux measurements, the mass flow rate of fuel is determined at each axial position by integrating over all values of the radial coordinate, r. The results normalized by the inlet flow rate are presented in Fig. 35 with some values obtained from the literature (Sellens, 1990). The experiment conducted by Sellens was not performed under identical conditions as those reported here, but the data demonstrate the difficulty in measuring volume fluxes close to the nozzle using PDI. Note that the volumetric flow rates obtained by integrating the volume flux are much lower than one would expect near the nozzle, but further downstream the results are reasonable, ranging from $60 \%$ to $80 \%$ of the inlet fuel flow rate. A large tangential component of the droplet velocity near the nozzle, for example, would 
introduce errors into the calculation of the probe volume (as discussed above), and would contribute to the low values of the integrated mass flux that are observed in Fig. 35. Further downstream, where the tangential component of the velocity has decreased, the error would not be as pronounced. However, similar results were reported by Bulzan et al. (1992) for non-swirling conditions, which indicate that if the tangential component of velocity is contributing to the error it is not the only important factor.

If the data obtained in this study are to be used for input and validation of multiphase combustion models, the lower values of the droplet volume fluxes shown in Fig. 30 must be corrected for these effects. The typical manner in which this is accomplished is to scale the number densities and fluxes presented in Figs. 29 and 30 so that the mass flow rate at $z=5 \mathrm{~mm}$ is consistent with the inlet fuel flow rate. This procedure appears reasonable, and is understandable when one considers the lack of alternatives. However, we note that this scaling procedure may introduce significant errors into the assumed spray distribution. If this procedure is adopted to specify inlet conditions for CFD models, it may be impossible to obtain satisfactory agreement between the computational results and the experimental data. Figure 36 illustrates the difficulties associated with this procedure. The number distribution and mass distribution obtained during one experimental run are shown in the figure. While the experimental data appear to capture the number distribution satisfactorily, the mass distribution is clearly truncated for diameters greater than $60 \mu \mathrm{m}$. The polydispersity of the spray makes it difficult to accurately measure both number and mass distributions, and much better results are obtained for monodisperse sprays. Unfortunately, an accurate representation for the number distribution that accounts for all of the fuel entering the reactor is critical for CFD models. Scaling the measured fluxes as is commonly done may result in overestimating the number of small droplets because a few large droplets, which can contain a non-negligible mass fiaction of the fuel, are neglected.

In this report, spray flame measurements are presented for the purpose of validating spray combustion models and submodels. However, it is necessary to quantify the measurement uncertainties if these data are to be compared with multiphase combustion models. The expressed uncertainties follow the guidelines put forth by NIST (Taylor and Kuyatt, 1994) and the National Conference of Standards Laboratories (1998). Uncertainties are classified as random (Type A) or systematic (Type B), and it is assumed that the combined variance $\left(s^{2}\right)$ is the $\mathbf{s} u m$ of the component variances. 
There are many factors that contribute to the uncertainties of PDI measurements such as uncertainties associated with the beam separation, transmitting lens focal length, receiving lens focal length, scattering angle, and others. Sellens (1990) summarized the various contributions and provided quantitative estimates for his system. Sellens concluded that the systematic uncertainties for the system he used were $4 \%$ and $3 \%$ for the velocity and size measurements, respectively. These uncertainties are lower than those reported by Bulzan (1995), who used a system similar to the one used for the experiments reported here. Bulzan estimated the drop size uncertainty in an isothermal monodisperse drop stream to be $6.5 \%$ and noted that it would probably be larger in an evaporating, polydisperse spray. McDonell and Samuelsen (1990) reported that the size error due to variation in the refractive index of a methanol spray when the temperature was varied from room temperature to the boiling point was $3.5 \%$. Because the experiments described here were conducted with methanol, and with the same scattering angle as that used by McDonell and Samuelsen, we will use this estimate of the uncertainty. Bulzan reported an estimated uncertainty in the velocity measurements of $10 \%$. Taylor et al. (1994) examined the errors associated with PDI measurements using monodisperse polystyrene latex (PSL) spheres ranging in diameter fiom $0.7 \mu \mathrm{m}$ to $10 \mu \mathrm{m}$. They found the systematic error of the instrument to be a strong function of particle size, with errors greater than $50 \%$ for $d_{p}=\mathbf{0 . 7} \mu \mathrm{m}$ and errors in the range $7 \%-14 \%$ for PSL spheres with $d_{p}>1 \mu \mathrm{m}$.

Droplet number density and flux measurements are the most difficult to make because they require accurate measurements of droplet size, droplet velocity, and probe volume. Also, the number density and volume flux measurements are strongly dependent on the small and large droplets, respectively. The probe volume is a function of the droplet diameter due to the Gaussian intensity profile of the laser beams as discussed above. The PDI software attempts to correct for the size dependence; however, the manufacturer reports an uncertainty of $\mathbf{7 . 5} \%$ in determining the sample volume (Aerometrics, 1987). In addition, multiple particles can occupy the probe volume simultaneously which will result in the signal being rejected and the number density being under-reported. This is not expected to be a significant source of error in the measurements presented in this report because the number of rejections was very small $(<0.5 \%)$ when the sizing was turned off and only the velocity components were measured. If multiple droplets occupied the probe volume simultaneously the signal would have been rejected during these velocity measurements. 
When using diagnostic techniques based upon light scattering in flames, there is the possibility that local variations in the refiactive index due to temperature and concentration variations can result in beam steering. The PDI manufacturer has investigated beam steering in flames and reports that the effect on the measurements is not critical (Taylor et al., 1994). Beam steering can result in a loss of signal so that the number density and volume flux measurements may be too low; however, this is not expected to introduce significant errors into the size and velocity measurements.

Table 9 summarizes the uncertainty budget for the PDI measurements. There are several points that deserve attention. First, the random errors associated with repeated measurements (Type A) are much less than the systematic errors (Type B). The repeatability of the measurements reported in this paper was very good, which resulted in consistent results during the several month period while data were collected. Unfortunately, the systematic errors associated with the phase Doppler interferometer are much larger than the random errors. The result is that although the spray was consistent fiom one day to another, the ability to quantify the droplet size, velocity, number density, etc. is limited by the instrument. Second, it should be noted that the uncertainties associated with the number density and volume flux measurements are much greater than those associated with the size and velocity measurements. This is true of both Type A and Type B errors.

\subsection{Exhaust Chemical Species Measurements}

The absorption spectra obtained with the FTIR spectrometer indicate that combustion was incomplete. Major species identified by the FTIR data include $\mathrm{CO}_{2}$, $\mathrm{CO}$ and $\mathrm{CH}_{3} \mathrm{OH}$. No minor components or reaction intermediates were identified perhaps due to the short path length. Figure 37 shows the mole fraction of $\mathrm{CO}_{2}, \mathrm{CO}$, and $\mathrm{CH}_{3} \mathrm{OH}$ at the exit plane of the reactor (see Fig. 1). The species concentrations are fairly uniform across the reactor exit plane, suggesting that there is good mixing in this region. Also, the concentration of $\mathbf{C 0 2}$ is approximately $\mathbf{5 0}$ times greater than that of $\mathrm{CO}$, which indicates that the rate of methanol conversion to $\mathbf{C 0 2}$ and $\mathbf{H 2 0}$ is occurring at a rate approximately 50 times faster than the conversion to $\mathrm{CO}$ and $\mathrm{H}_{2} \mathbf{O}$. The uncertainty budget for the species concentration measurements is presented in Table 10 . The concentrations of $\mathrm{NO}_{2}$ and $\mathbf{N 2 0}$ were too low to detect with the FTIR measurements. A NO, analyzer is being installed to measure the concentrations of these chemical species. 
Figure 38 presents theoretical species concentrations within the reactor emissions. The calculations were performed assuming that only two reactions were significant. These are the conversion of $\mathrm{CH}_{3} \mathrm{OH}$ to $\mathrm{CO}_{2}$ and the conversion of $\mathrm{CH}_{3} \mathrm{OH}$ to $\mathrm{CO}$. The rate of $\mathrm{C} 02$ production is assumed to be 50 times faster than the production of $\mathrm{CO}$, which was shown above to be consistent with the FTIR data. The filled circles in Fig. 38 show the measured concentrations of $\mathrm{CO}, \mathrm{CO}_{2}$, and $\mathrm{CH}_{3} \mathrm{OH}$. These are spatially averaged values obtained from Fig. 37. The velocity profiles were not required for these calculations because of the spatially uniform species concentrations. The comparison of experimental data and theoretical calculations in Fig. 38 show that the conversion of $\mathrm{CH}_{3} \mathrm{OH}$ is $\sim 80 \%$, and that mass is conserved in the system.

\section{Summary}

Experimental data with uncertainty budgets were obtained from a reacting methanol spray under well-characterized conditions for the purpose of validating multiphase combustion models and submodels. Input and boundary conditions are provided for a defined baseline case. Droplet size and velocity distributions, number densities, and volume fluxes were measured; however, the uncertainty associated with the number density and volume flux measurements are considered high. Gas-phase species measurements were made using FTIR spectroscopy, and provide exhaust concentrations of $\mathrm{CO}, \mathrm{CO}_{2}$, and $\mathrm{CH}_{3} \mathrm{OH}$. The species measurements indicate that the conversion of methanol in the reactor is $\sim 80 \%$. Wall temperature data are provided as a function of axial position, as well as the temperature of the exhaust gas. Gas-phase velocity, temperature, and heat flux measurements are planned for the next stage of this investigation. 


\section{References}

Afeefy H. Y., Liebman J. F., and Stein S. E., "Neutral Thermochemical Data" in MST Chemistry WebBook, NIST Standard Reference Database Number 69, Eds. W.G. Mallard and P.J. Linstrom, March 1998, National Institute of Standards and Technology, Gaithersburg MD, 20899.

American National Standard for Expressing Uncertainty - U.S. Guide for the Expression of Uncertainty in Measurement. (1998). National Conference of Standards Laboratories.

Bachalo, W. D. and Houser, M. J. (1984a). Development of the Phase/Doppler Spray analyzer for Liquid Droplet Size and Velocity Characterizations, AIAA/SAE/ASME $20^{\text {th }}$ Joint Propulsion Conference. June 11-13,1984. Cincinnati, Chio USA.

Bachalo, W. D. and Houser, M. J. (1984b). Phase/Doppler Spray Analyzer for Simultaneous Measurements of Droplet Size and Velocity Distributions, Optical Engineering. 23:583-590.

Bachalo, W. D., Rudoff, R. C., and Brena de la Rosa, A. (1988). Mass Flux Measurements of a High Number Density Spray System Using the Phase Doppler Particle Analyzer, ALAA $26^{\text {th }}$ Aerospace Sciences Meeting, January 11-14, 1998. Reno, NV.

Beér, J. M. and Chigier, N. A. (1972). Combustion Aerodynamics, Applied Science Publishers, London, England UK.

Bulzan, D. L. (1995). Structure of a Swirl-Stabilized Combusting Spray, J. Prop. Power. 11:1093-1102.

Bulzan, D. L., Levy, Y., Aggarwal, S. K., and Chitre, S. (1992). Measurements and Predictions of a Liquid Spray from an Air-Assist Nozzle, Atomization and Sprays, 2:445-162.

Gupta, A. K., Lilley, D. G., and Syred, N. (1984). Swirl Flows, Abacus Press, Kent, England UK. 
McDonell, V. G., and Samuelsen, G. S. (1990). Application of Laser Interferometry to the Study of Droplet/Gas Phase Interaction and Behavior in Liquid Spray Combustion Systems, Combust. Sci. and Tech. 74:343-359.

Oberkampf, W. L., Sindir, M. M., and Conlisk, A. T. (1997). "Guide for the Verification and Validation of Computational Fluid Dynamics Simulations." American Institute of Aeronautics and Astronautics. Guide G-077-98.

Phase Doppler Particle Analyzer - Operations Manual, Release 3.0. Aerometrics Inc. Mountain View, CA. August 1987.

Presser, C., Gupta, A. K., Avedisian, C. T., and Semerjian, H. G. (1994). Effect of Dodecanol Content on the Combustion of Methanol Spray Flames. Atomization and Sprays. 4 207-222.

Presser, C., Gupta, A. K., and Semerjian, H. G. (1993). Aerodynamic Characteristics of Swirling Spray Flames: Pressure-Jet Atomizer, Combust. Flame. 92:25-44.

Sellens, R. W. (1990). Phase-Doppler Measurements Near the Nozzle in a LowPressure Water Spray, Liquid Particle Size Measurement Techniques: 2nd Volume, ASTM STP 1083, E. D. Hirleman, W. D. Bachalo, and P. G. Felton, Eds. ASTM, Philadelphia, PA. p. 193-208.

Taylor, B. N., and Kuyatt, C. E. (1994). Guidelines for Evaluating and Expressing the Uncertainty of NIST Measurement Results. NIST Technical Note 1297, 1994 Edition.

Taylor, P., Dudek, R., Flaherty, D., and Kaempfe, T. (1994). Evaluation of Two Instruments for the Measurement of Aerosols, J.Aerosol Sci. 25:419-423.

van de Hulst, H. C. (1957). Light Scattering by Small Particles. John Wiley and Sons, Inc., NY. 
Widmann, J. F., Charagundla, S. R., Presser, C., Yang, G., and Leigh, S. D. (1999). Spray Intensity Measurements Using Phase Doppler Interferometry, Atomization \& Sprays, submitted.

Zhu, J. Y., Rudoff, R. C., Bachalo, E. J., and Bachalo, W. D. (1993). Number Density and Mass Flux Measurements Using the Phase Doppler Particle Analyzer in Reacting and Non-Reacting Swirling Flows, $31^{\text {st }}$ Aerospace Sciences Meeting \& Exhibit, January 11-14,1993. Reno, NV. 
Table 1. Operating conditions for the baseline case.

\begin{tabular}{|c|c|}
\hline Fuel Type & Methanol \\
\hline Fuel Flow Rate & $3.0 \mathrm{~kg} \mathrm{~h}^{-1}$ \\
\hline Fuel Temperature & Ambient \\
\hline Equivalence Ratio & 0.3 \\
\hline Air Temperature & Ambient \\
\hline Vane Angle & $50^{\circ}$ \\
\hline Swirl Number & $\begin{array}{c}0.47 \text { (geometrical correlation) } \\
\mathbf{0 . 5 4}(\mathrm{CFD} \text { results) }\end{array}$ \\
\hline Flame Standoff Distance & $\sim 5 \mathrm{~mm}$ \\
\hline Chamber Pressure & Ambient \\
\hline
\end{tabular}


Table 2. Uncertainty budget for the location of PDI probe volume.

\begin{tabular}{|c|c|}
\hline \multirow{2}{*}{$\begin{array}{c}\text { Source of } \\
\text { uncertainty }\end{array}$} & $\begin{array}{c}\text { Standard } \\
\text { uncertainty } \\
(\mathrm{mm})\end{array}$ \\
\cline { 2 - 3 } axial position, $\Delta z$ & Type B \\
\hline horizontal position, $\Delta \mathrm{x}$ & 0.17 \\
\hline horizontal position, $\Delta \mathrm{y}$ & 0.083 \\
\hline Spray angle, $\Delta \theta$ & 0.17 \\
\hline radial coordinate, $\Delta \mathrm{r}$ & $0.33^{\circ}$ \\
\hline
\end{tabular}


Table 3. Uncertainty budget for the fuel flow rate $\left(3.0 \mathrm{~kg} \mathrm{hr}^{-1}\right)$.

\begin{tabular}{|c|c|c|}
\hline \multirow{2}{*}{$\begin{array}{l}\text { Source of } \\
\text { uncertainty }\end{array}$} & \multicolumn{2}{|c|}{$\begin{array}{c}\text { Standard } \\
\text { uncertainty } \\
\left(\mathrm{kg} \mathrm{hr}^{-1}\right)\end{array}$} \\
\hline & Type A & Type B \\
\hline $\begin{array}{l}\text { fuel flow / turbine frequency } \\
\text { calibration }\end{array}$ & & 0.0042 \\
\hline turbine meter / DAQ signal & & 0.0020 \\
\hline repeated observations & 0.015 & \\
\hline
\end{tabular}


Table 4. Uncertainty budget for the combustion air flow rate $\left(56.7 \mathrm{~m}^{3} \mathrm{hr}^{-1}\right)$.

\begin{tabular}{|c|c|c|}
\hline \multirow{2}{*}{$\begin{array}{l}\text { Source of } \\
\text { uncertainty }\end{array}$} & \multicolumn{2}{|c|}{$\begin{array}{c}\text { Standard } \\
\text { uncertainty } \\
\left(\mathrm{m}^{3} \mathrm{hr}^{-1}\right)\end{array}$} \\
\hline & TypeA & TypeB \\
\hline $\begin{array}{l}\text { flow rate / pressure calibration } \\
\text { reported by manufacturer }\end{array}$ & & 1.70 \\
\hline pressure / voltage calibration & & 0.252 \\
\hline $\begin{array}{l}\text { comparison with calibrated } \\
\text { pressure gauge }\end{array}$ & & 0.170 \\
\hline repeated observations & 0.024 & \\
\hline
\end{tabular}


Table 5. Wall temperatures.

\begin{tabular}{|c|c|c|}
\hline Thermocouple & $\begin{array}{c}\text { Height } \\
(\mathrm{mm})\end{array}$ & $\begin{array}{c}\text { Mean } \\
\text { Temperature } \\
\left({ }^{\circ} \mathrm{C}\right)\end{array}$ \\
\hline $\mathrm{TC} \# 1$ & 99 & 93 \\
\hline $\mathrm{TC} \# 2$ & 165 & 93 \\
\hline $\mathrm{TC} \# 3$ & 231 & 95 \\
\hline $\mathrm{TC} \# 4$ & 297 & 99 \\
\hline $\mathrm{TC} \# 5$ & 429 & 103 \\
\hline $\mathrm{TC} \# 6$ & 561 & 112 \\
\hline $\mathrm{TC} \# 7$ & 693 & 114 \\
\hline $\mathrm{TC} \# 8$ & 826 & 121 \\
\hline $\mathrm{TC} \# 9$ & 958 & 133 \\
\hline $\mathrm{TC} \# 10$ & 1090 & \\
\hline
\end{tabular}


Table 6. Exit gas temperatures

\begin{tabular}{|c|c|c|}
\hline $\begin{array}{c}\text { Radial } \\
\text { Coordinate, } p \\
(\mathrm{~mm})\end{array}$ & $\begin{array}{c}\text { Polar } \\
\text { Angle, } \phi \\
(\mathrm{deg})\end{array}$ & $\begin{array}{c}\text { Mean } \\
\text { Temperature } \\
\text { (') })\end{array}$ \\
\hline $\mathbf{0}$ & - & 244 \\
\hline 44.5 & $\mathbf{0}$ & 265 \\
\hline 88.9 & $\mathbf{0}$ & $\mathbf{2 8 2}$ \\
\hline 133.4 & 0 & 288 \\
\hline 177.8 & 0 & 266 \\
\hline 44.5 & 90 & 251 \\
\hline 88.9 & 90 & 258 \\
\hline 133.4 & 90 & 271 \\
\hline 177.8 & 90 & 277 \\
\hline 44.5 & 180 & 221 \\
\hline 88.9 & 180 & 207 \\
\hline 133.4 & 180 & 182 \\
\hline 177.8 & 180 & 160 \\
\hline
\end{tabular}

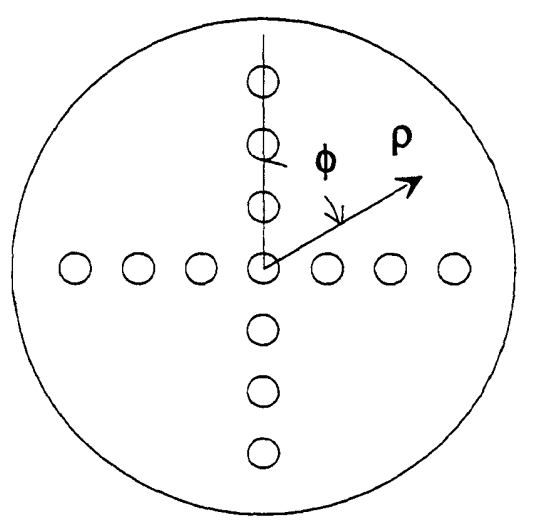

End Plate (see Fig. 1). 
Table 7. Uncertainty budget for the temperature measurements.

\begin{tabular}{|c|c|c|}
\hline \multirow{2}{*}{$\begin{array}{c}\text { Source of } \\
\text { uncertainty }\end{array}$} & \multicolumn{2}{|c|}{$\begin{array}{c}\text { Standard } \\
\text { uncertainty } \\
\left({ }^{\circ} \mathrm{C}\right)\end{array}$} \\
\cline { 2 - 3 } & TypeA & TypeB \\
\hline uncertainty reported \\
by the manufacturer & & \\
\hline repeated observations & 2.2 & \\
wall temperature & $<2.0$ & \\
gas temperature & $<5.0$ & \\
\hline \hline \multicolumn{2}{|c|}{ Combined standard uncertainty: } \\
wall temperature \\
gas temperature \\
\hline \multirow{2}{*}{3.0} \\
5.5 \\
\hline
\end{tabular}


Table 8. ASCII data file format

\begin{tabular}{|c|c|}
\hline File Name & $\begin{array}{l}\text { Axial Coordinate, } z \\
\text { (mm) }\end{array}$ \\
\hline spray_1.dat & 5 \\
\hline spray_2.dat & 15 \\
\hline spray_3.dat & 25 \\
\hline spray_4.dat & 35 \\
\hline spray-5.dat & 45 \\
\hline spray_6.dat & 55 \\
\hline spray_7.dat & 65 \\
\hline Column & Variable \\
\hline 1 & Axial Coordinate, $\mathbf{z}(\mathrm{mm})$ \\
\hline 2 & Radial Coordinate, $r$ (mm) \\
\hline 3 & $\Delta \mathrm{r}(\mathrm{mm})$ \\
\hline 4 & Sauter Mean Diam, $D_{32}(\mu \mathrm{m})$ \\
\hline 5 & $\Delta \mathrm{D} 32(\mu \mathrm{m})$ \\
\hline 6 & Number Density, $\mathrm{N}_{d}\left(\mathrm{~cm}^{-3}\right)$ \\
\hline 7 & $\Delta \mathrm{N}_{\mathrm{d}}\left(\mathrm{cm}^{-3}\right)$ \\
\hline 8 & Volume Flux, $F_{v}\left(\mathrm{~cm}^{3} \mathrm{~cm}^{-2} \mathrm{~s}^{-1}\right)$ \\
\hline 9 & $\Delta F_{v}\left(\mathrm{~cm}^{3} \mathrm{~cm}-2 \mathrm{~s}-1\right)$ \\
\hline 10 & Spray Angle, $\theta$ (degrees) \\
\hline
\end{tabular}


Table 9. Uncertainty budget for the PDI measurements.

\begin{tabular}{|c|c|c|}
\hline \multirow{2}{*}{$\begin{array}{c}\text { Source of } \\
\text { uncertainty }\end{array}$} & \multicolumn{2}{|c|}{$\begin{array}{c}\text { Standard } \\
\text { uncertainty } \\
\text { (\%) }\end{array}$} \\
\cline { 2 - 3 } Type A & Type B \\
\hline $\begin{array}{c}\text { droplet size measurement: } \\
\text { repeated observations }\end{array}$ & 1.0 & \\
uncertainty reported in literature & $\mathbf{7 . 4}$ \\
\hline $\begin{array}{c}\text { droplet velocity measurement: } \\
\text { repeated observations }\end{array}$ & 1.5 & \\
uncertainty reported in literature & & \\
\hline $\begin{array}{c}\text { number density measurement: } \\
\text { repeated observations }\end{array}$ & 9.1 & \\
\hline volume flux measurement: \\
repeated observations
\end{tabular}


Table 10. Uncertainty budget for the species concentration measurements.

\begin{tabular}{|c|c|c|}
\hline \multirow[t]{2}{*}{$\begin{array}{l}\text { Source of } \\
\text { uncertainty }\end{array}$} & \multicolumn{2}{|c|}{$\begin{array}{l}\text { Standard } \\
\text { uncertainty } \\
\text { (ppm) }\end{array}$} \\
\hline & Type $\mathbf{A}$ & Type B \\
\hline calibrations & & \\
\hline $\begin{array}{l}\mathrm{CH}_{3} \mathrm{OH} \\
\mathrm{CO} \\
\mathrm{CO}_{2}\end{array}$ & & $\begin{array}{c}5 \times 10^{-5} \\
10^{-4} \\
10^{-3}\end{array}$ \\
\hline repeated observations & & \\
\hline $\begin{array}{l}\mathrm{CH}_{3} \mathrm{OH} \\
\mathrm{CO} \\
\mathrm{CO}_{2}\end{array}$ & $\begin{array}{l}4 \times 10^{-4} \\
7 \times 10^{-5} \\
4 \times 10^{-2}\end{array}$ & \\
\hline \multicolumn{3}{|c|}{ Combined standard uncertainty } \\
\hline $\mathrm{CH}_{3} \mathrm{OH}$ & \multicolumn{2}{|c|}{$4 \times 10^{-4}$} \\
\hline co & \multicolumn{2}{|c|}{$1.2 \times 10^{-4}$} \\
\hline $\mathrm{CO}_{2}$ & \multicolumn{2}{|c|}{$4.1 \times 10^{-3}$} \\
\hline
\end{tabular}



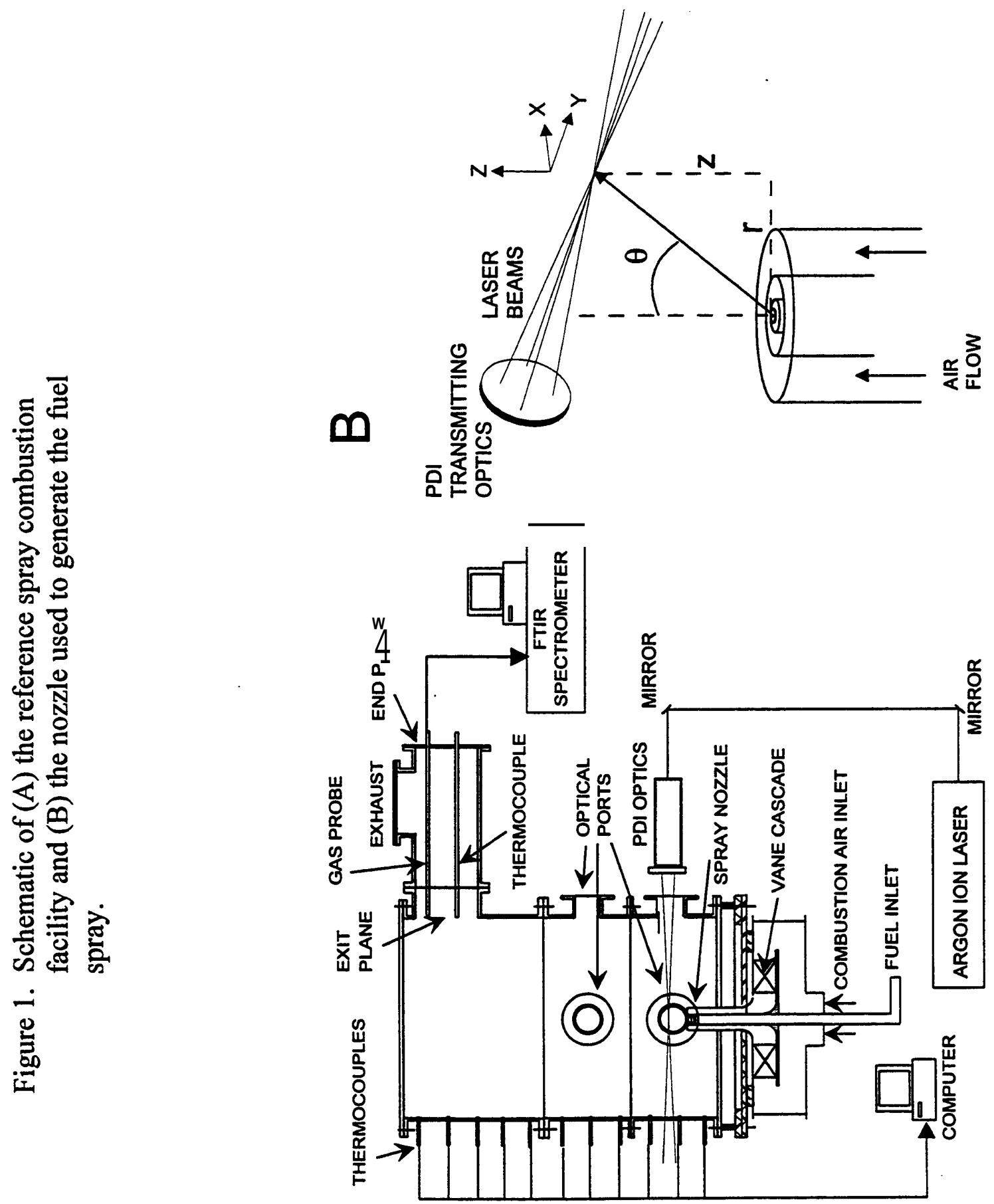

a 

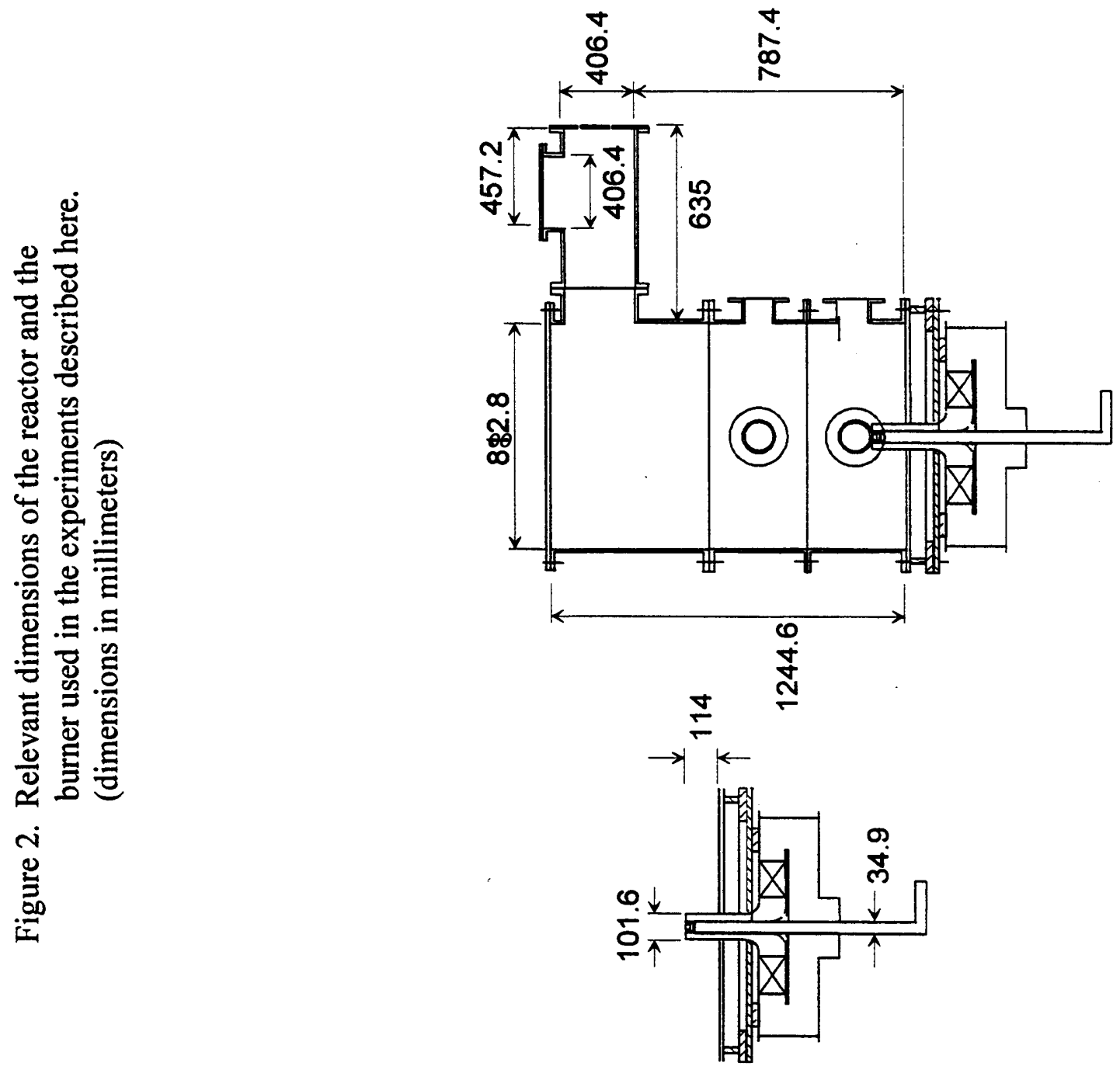
Figure 3. Schematic of the image observed through the viewing port of the PDI receiving optics when the probe volume is located at (A) $x=y=0$ and $z=1 \mathrm{~mm}$, and (B) $x=y=0$ and $\mathrm{z}=3 \mathrm{~mm}$.

A

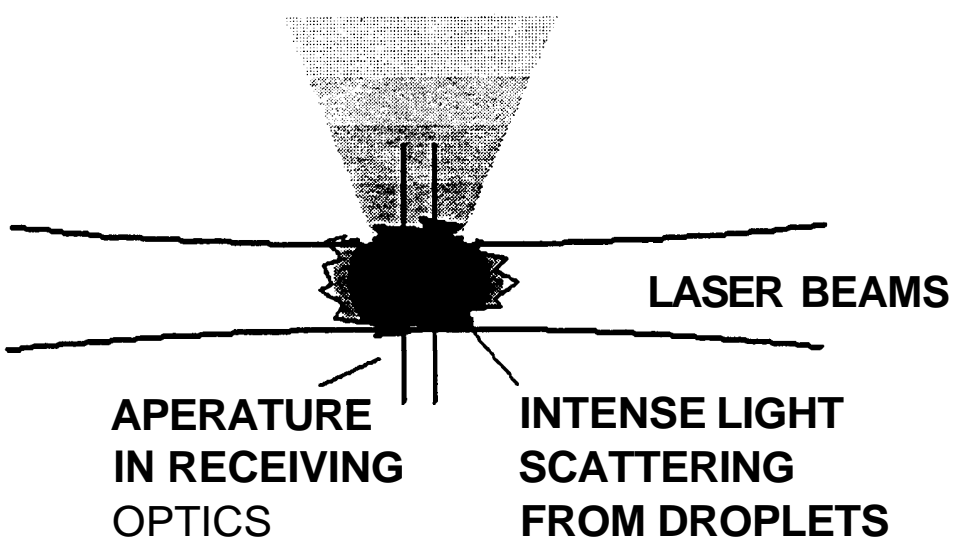

B

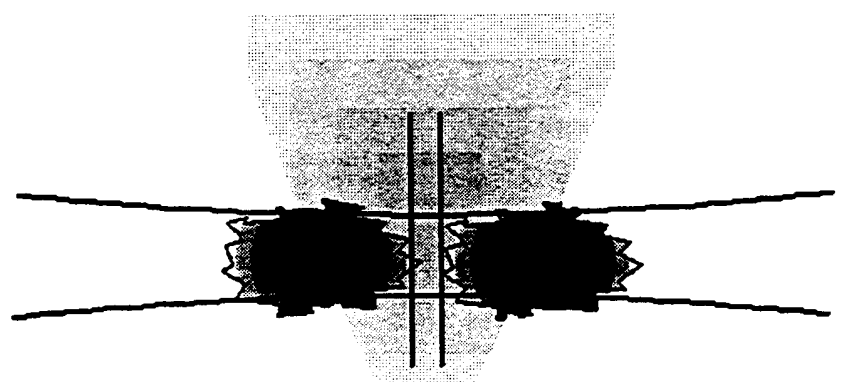


Figure 4. Droplet size distributionsat $z=5 \mathrm{~mm}$ and $r=2.76 \mathrm{~mm}$. Presented are (A) the raw data, (€3) the raw data with the cubic spline, and (C) the cubic spline with confidence bands.

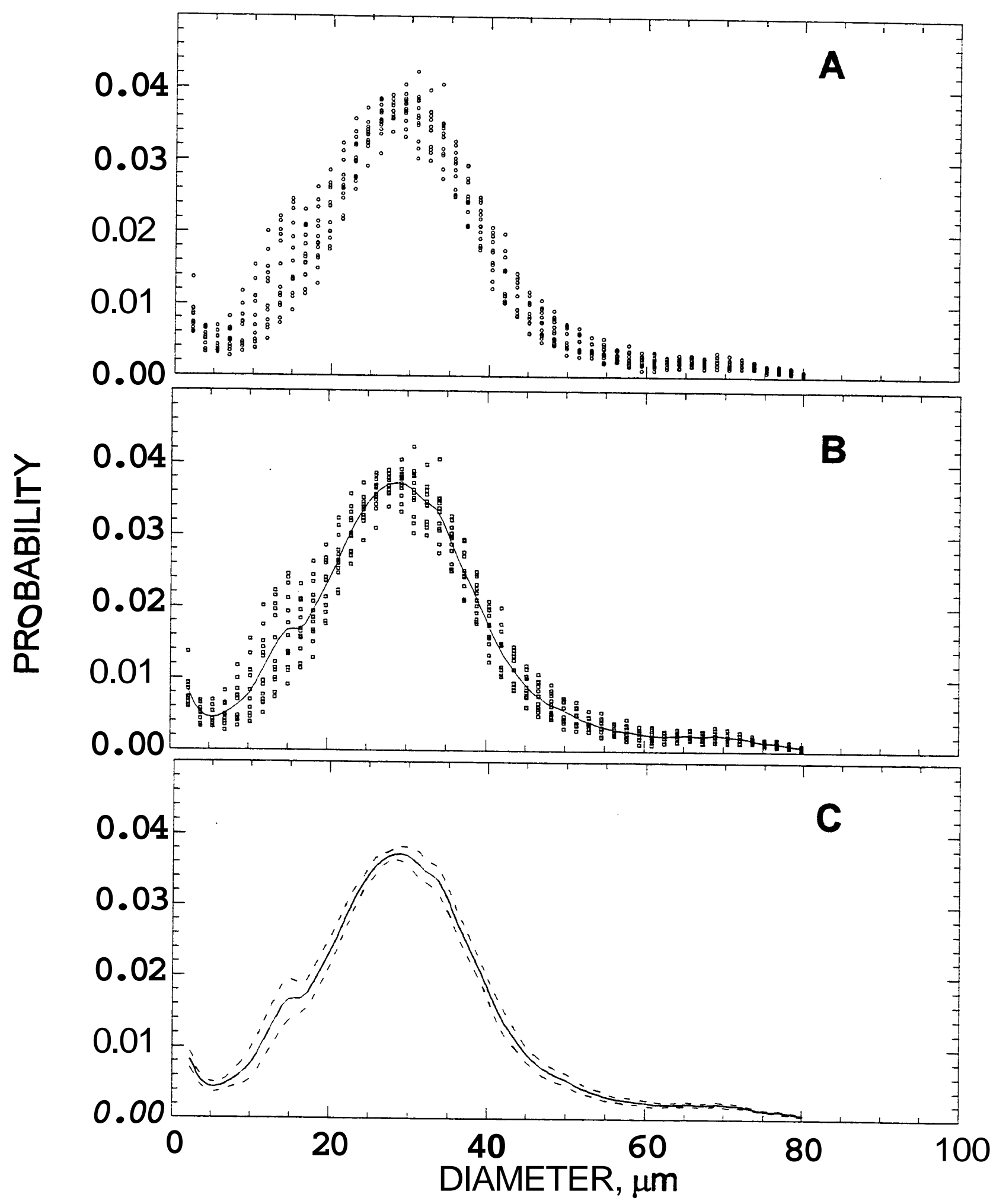




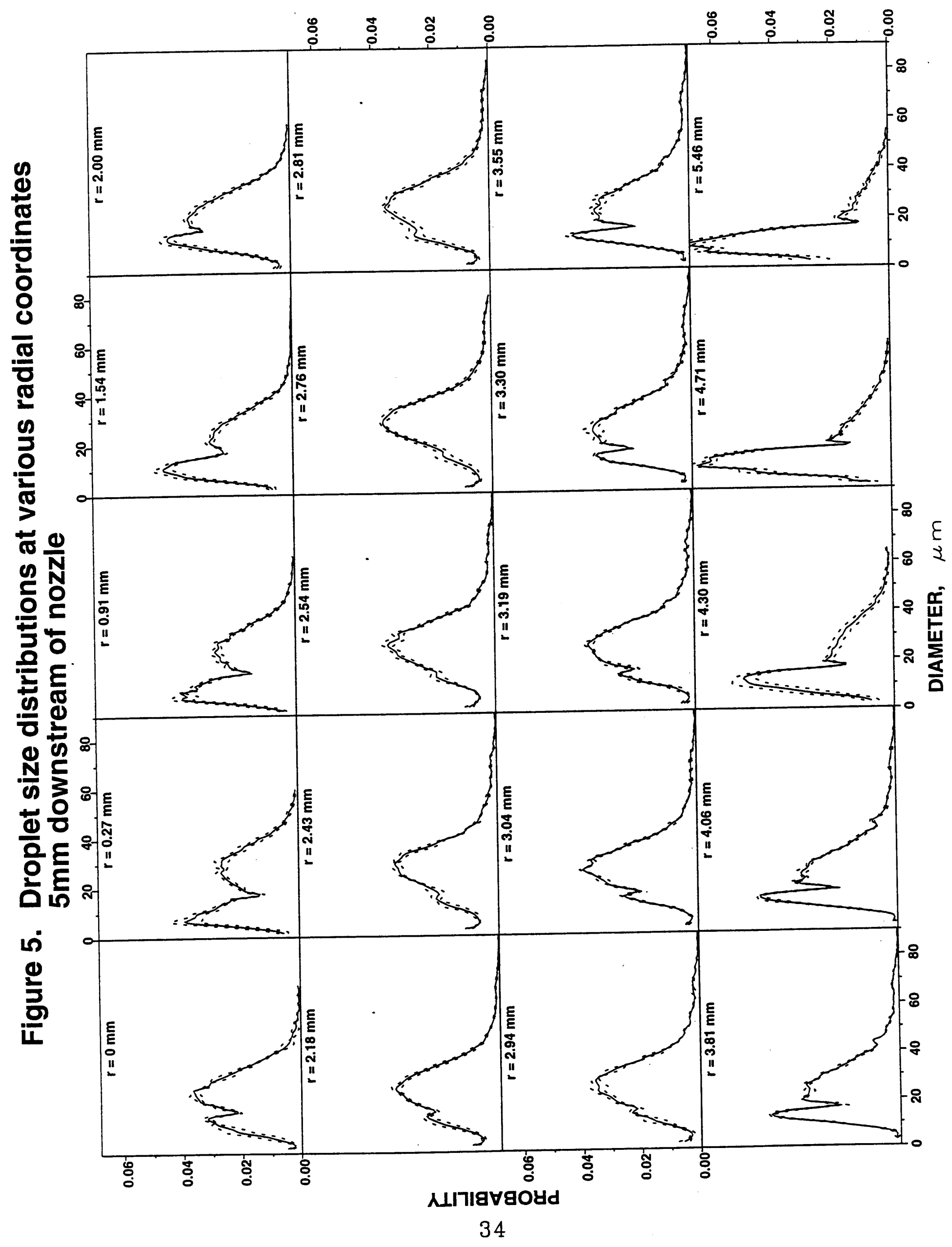




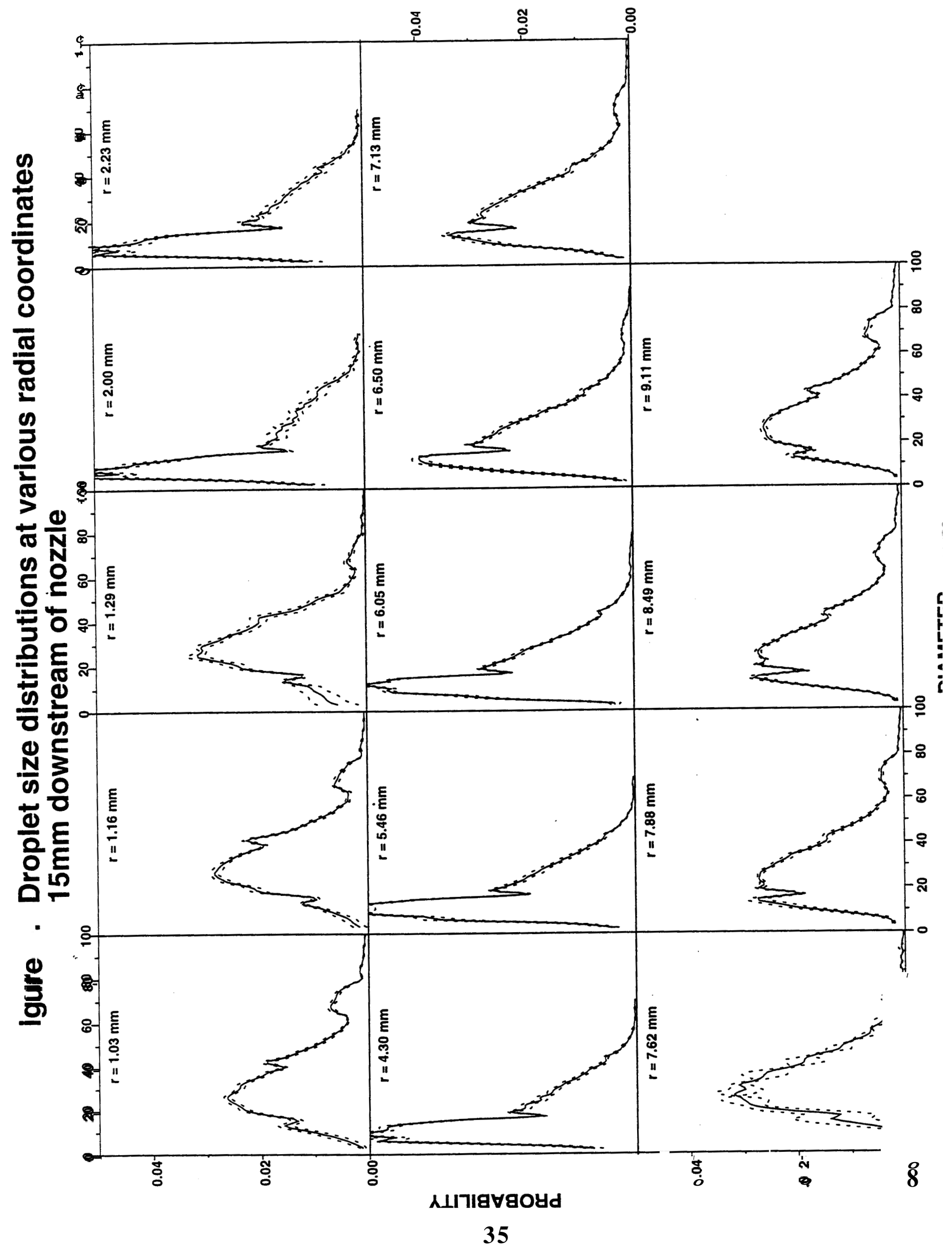




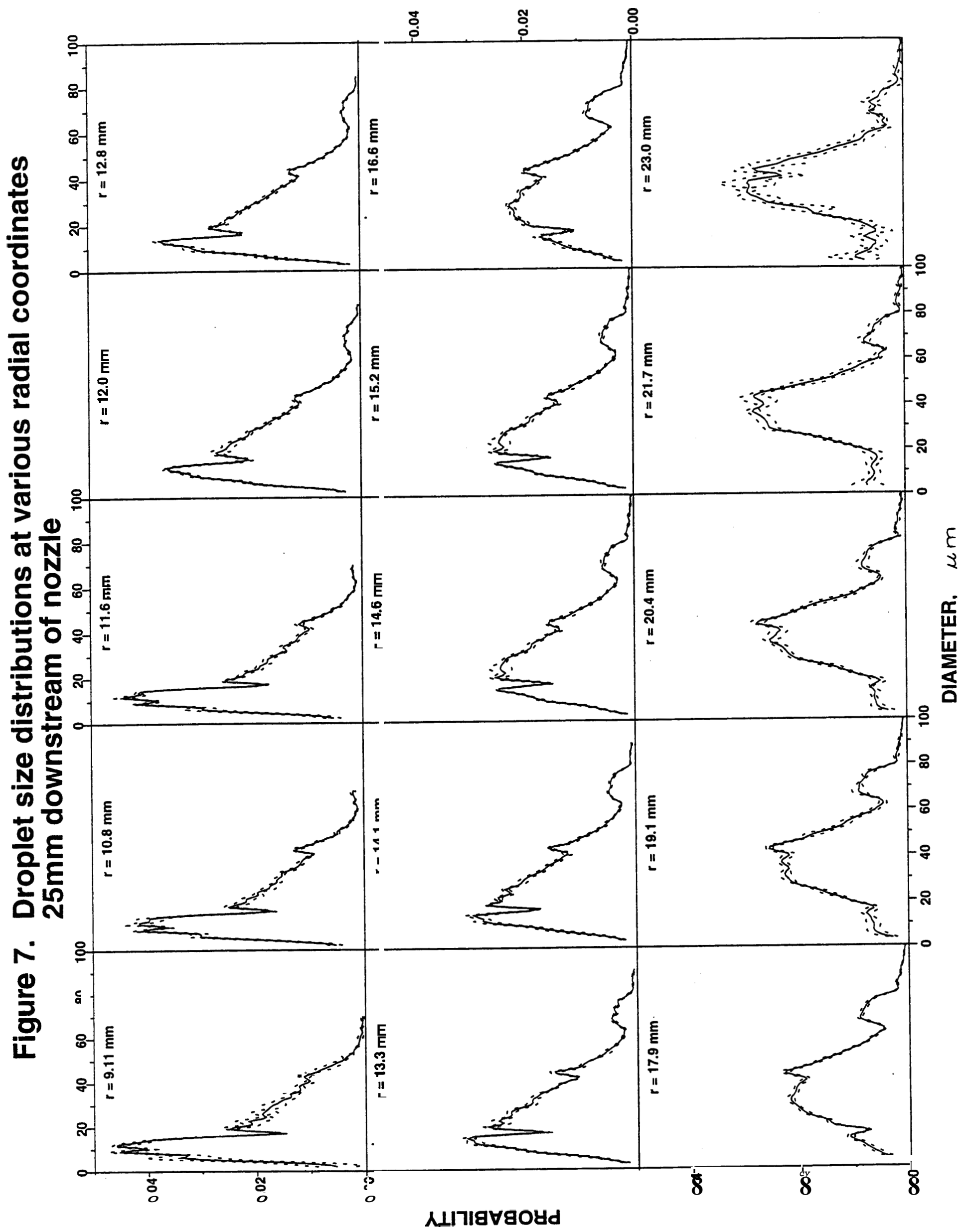




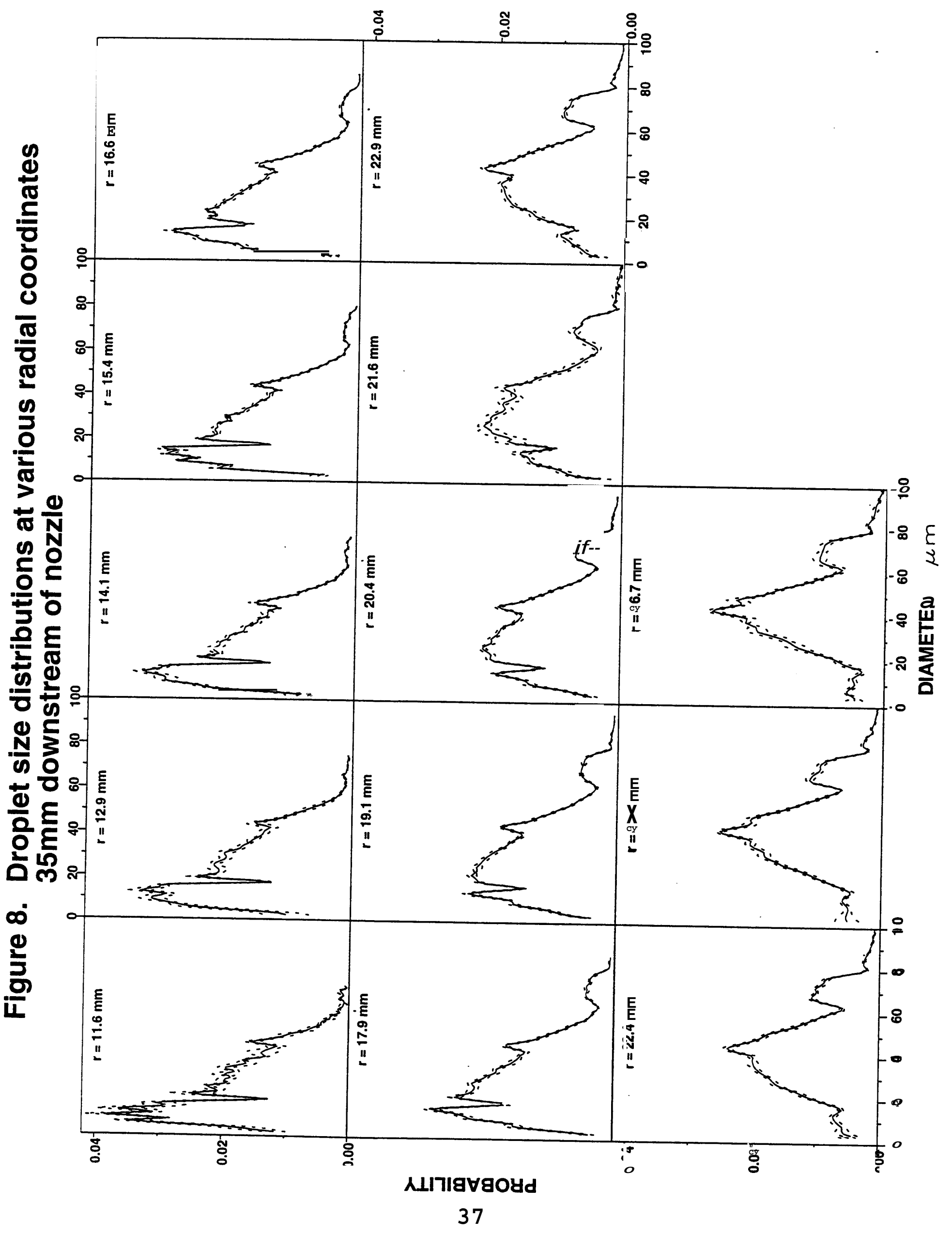




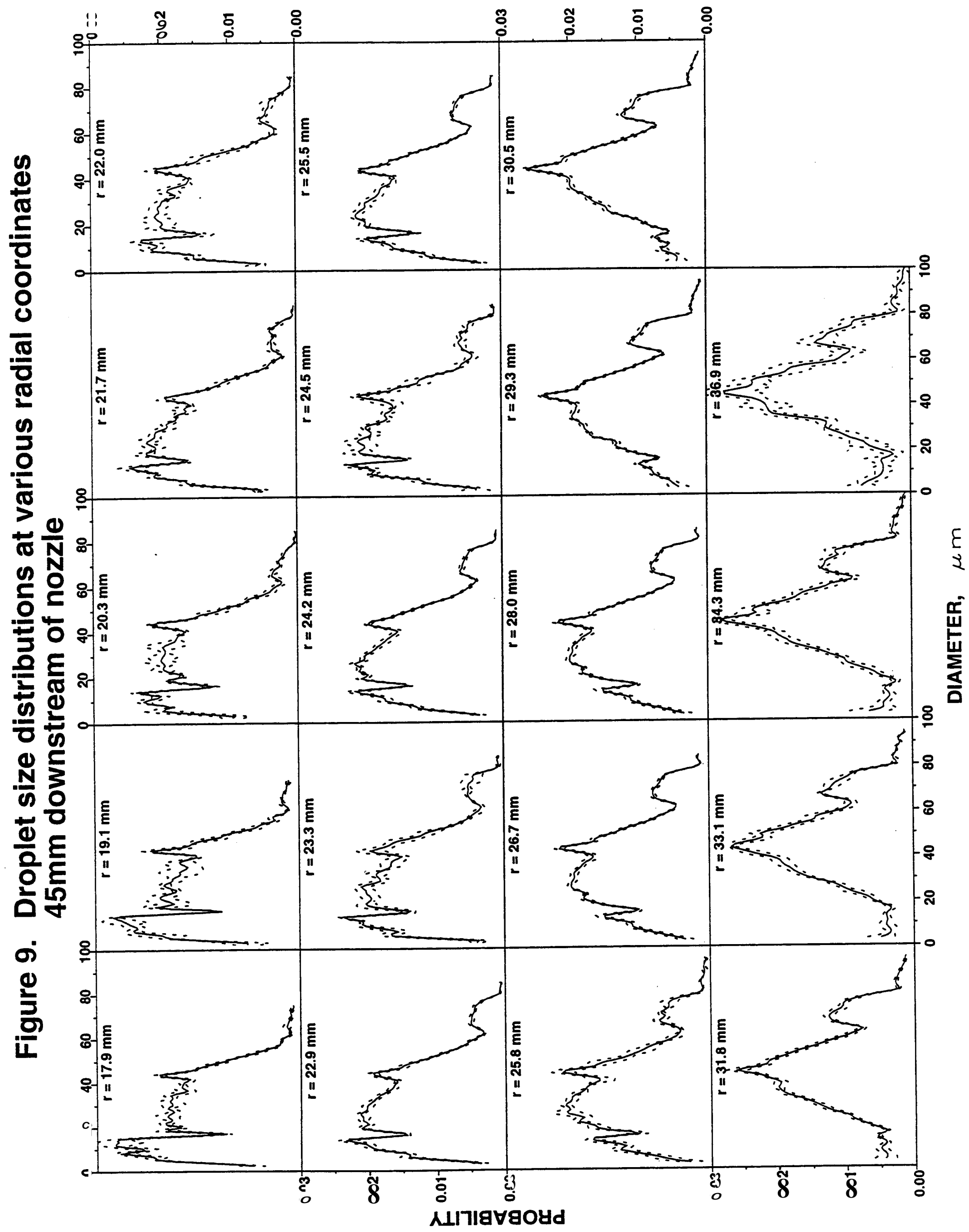




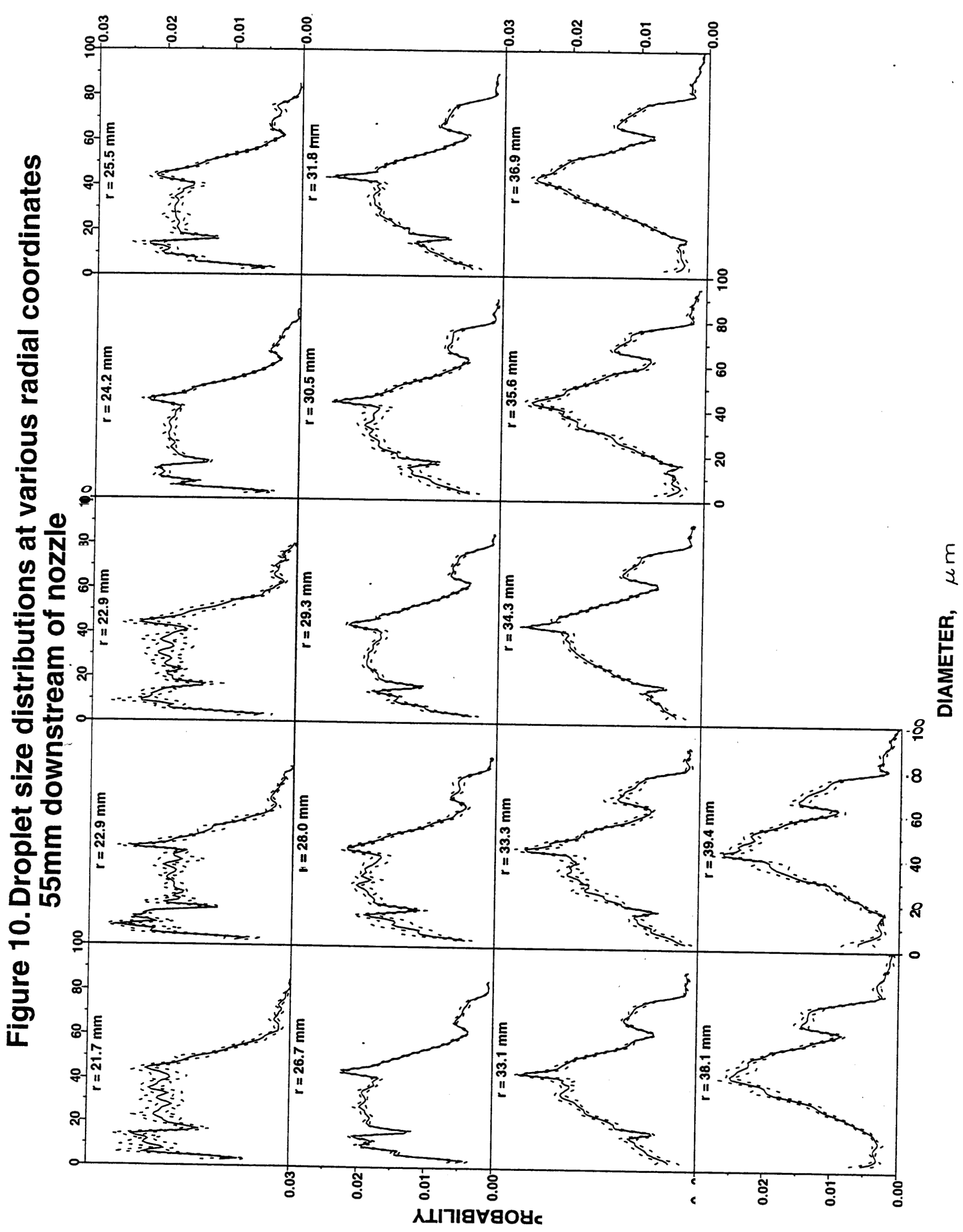




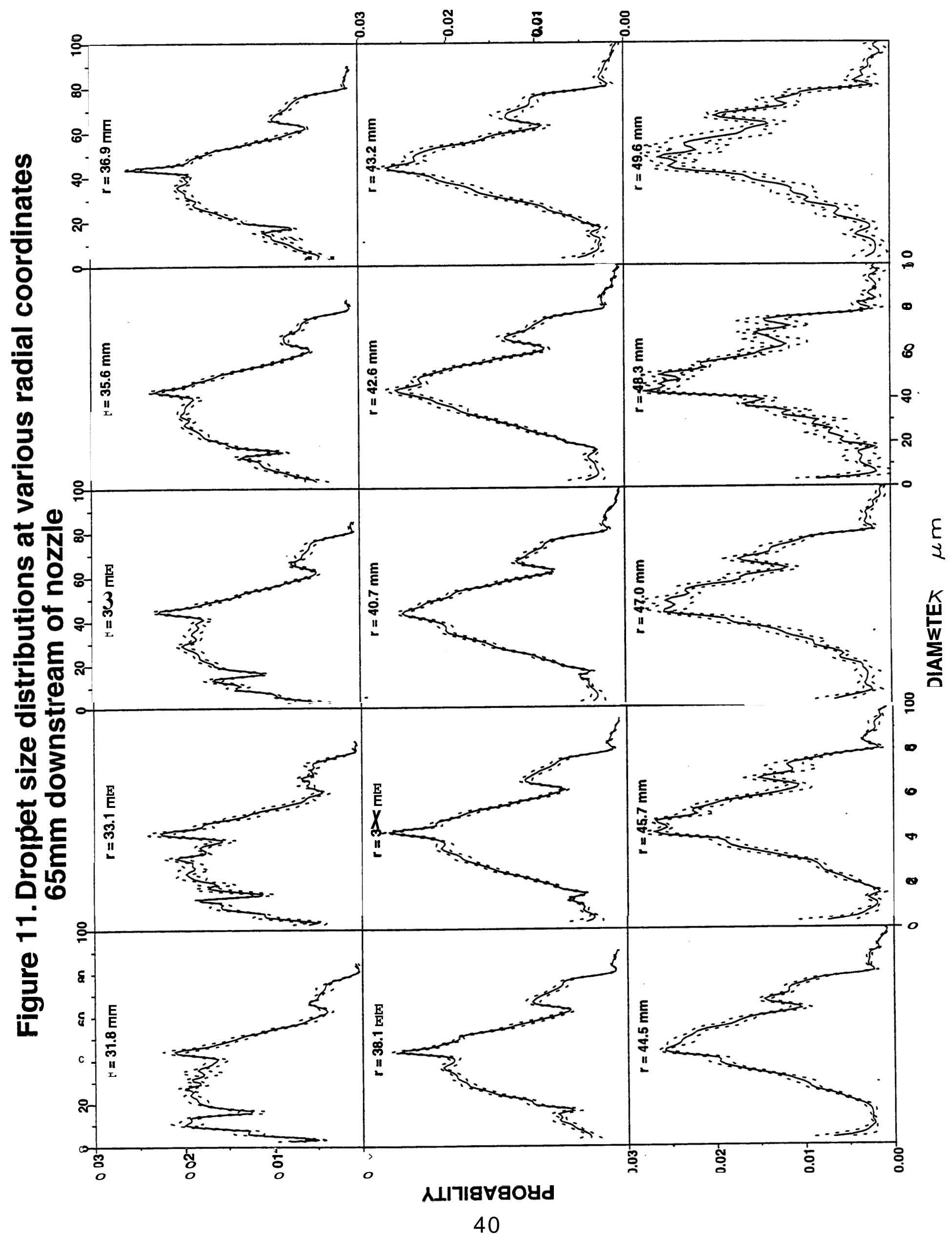




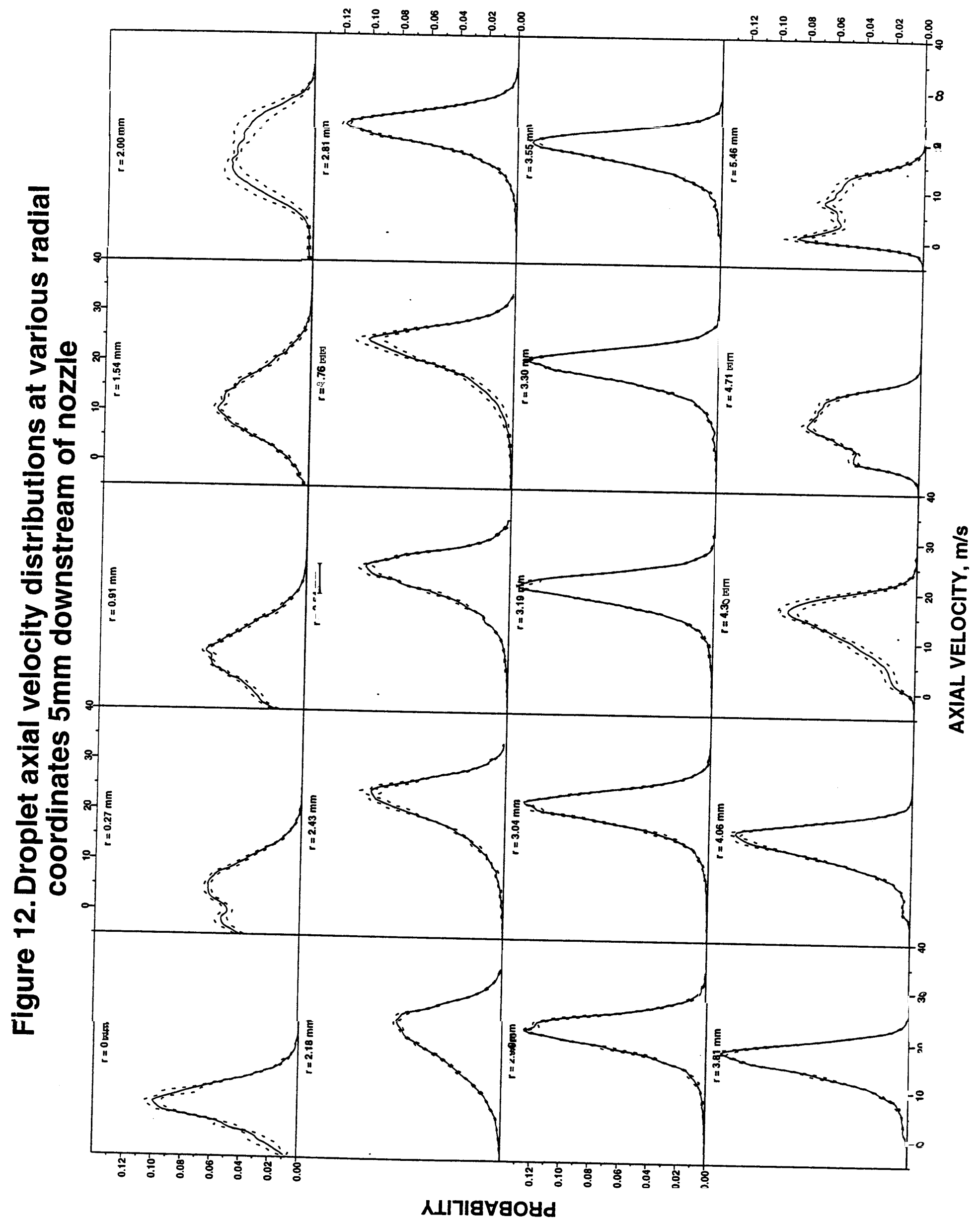




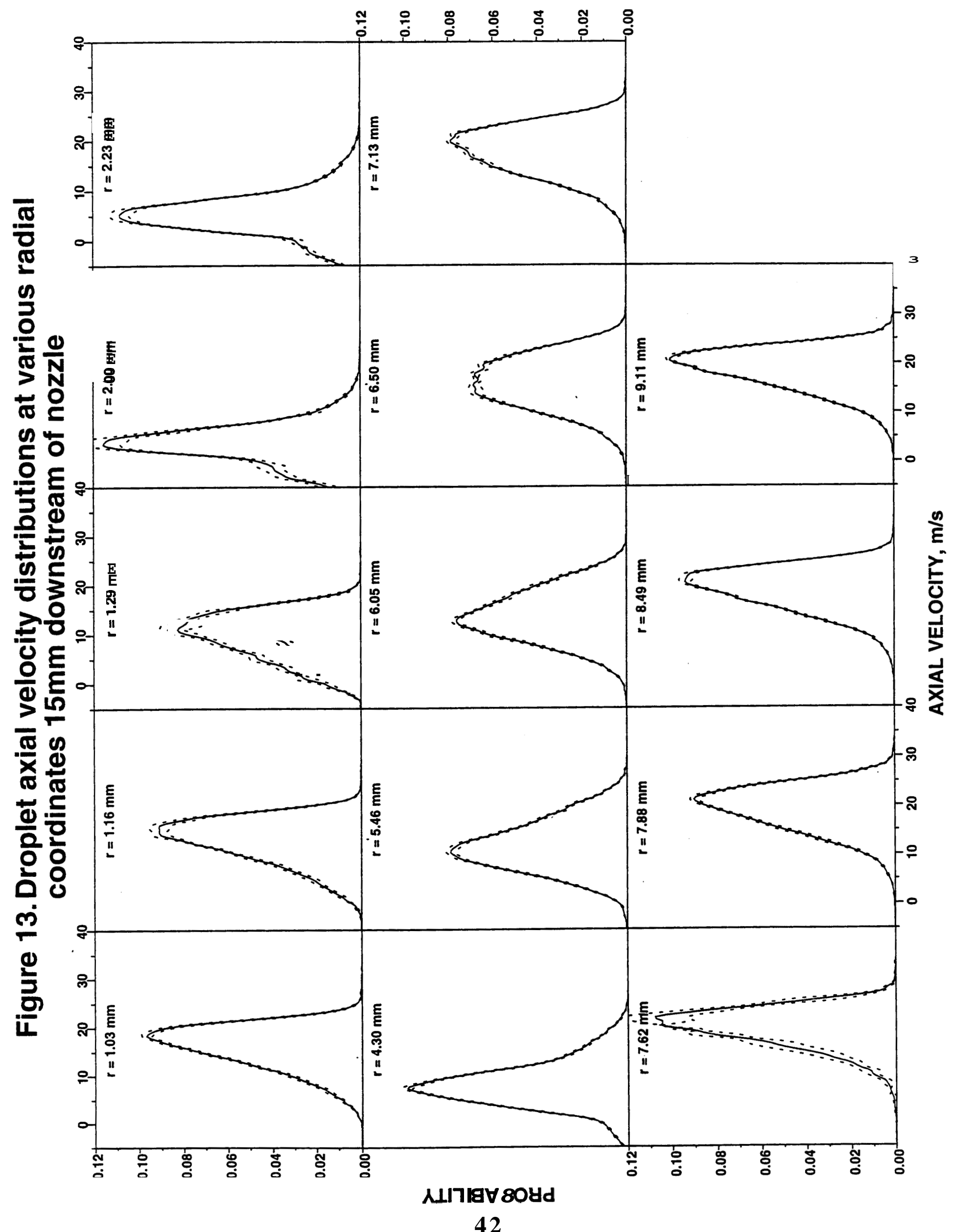




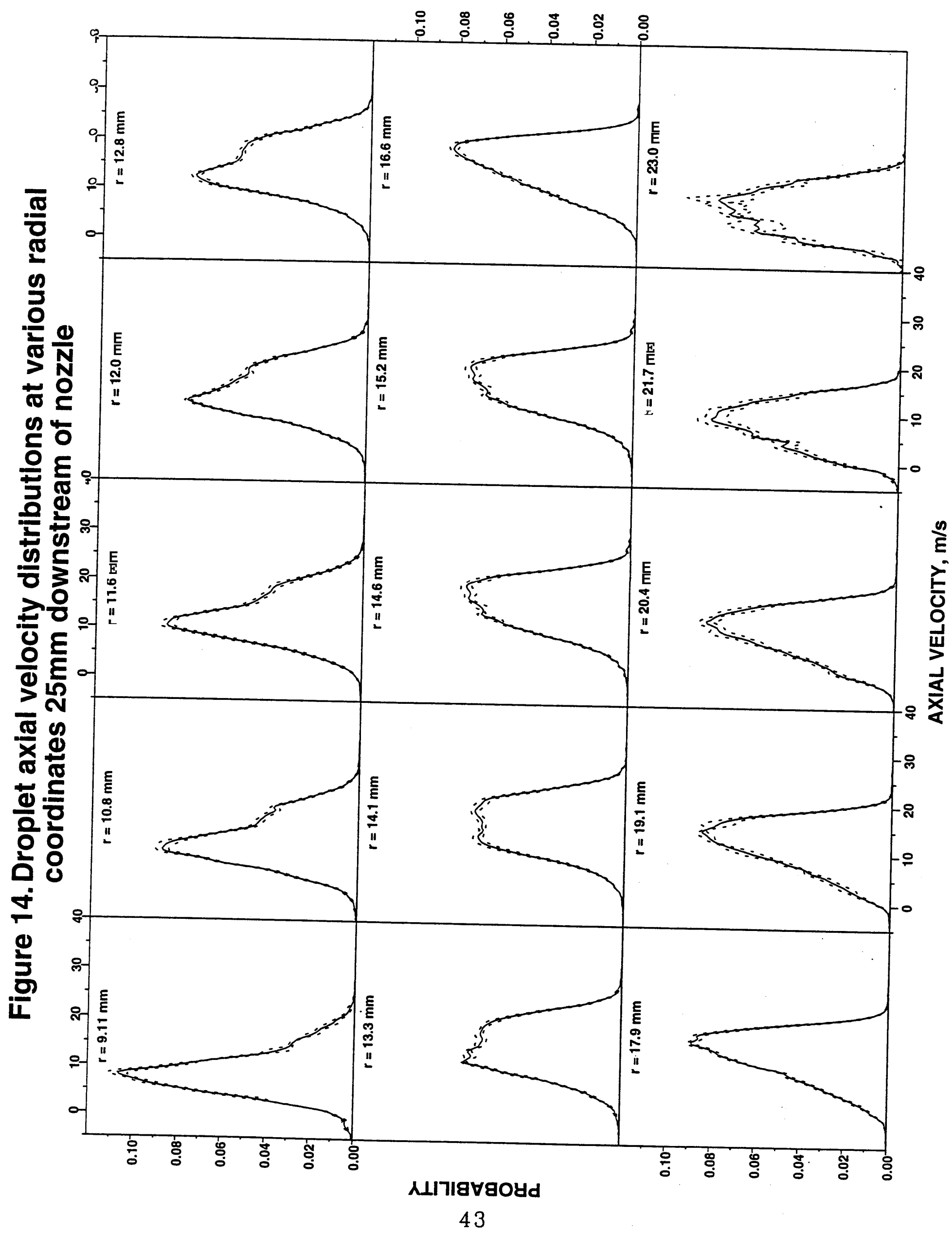




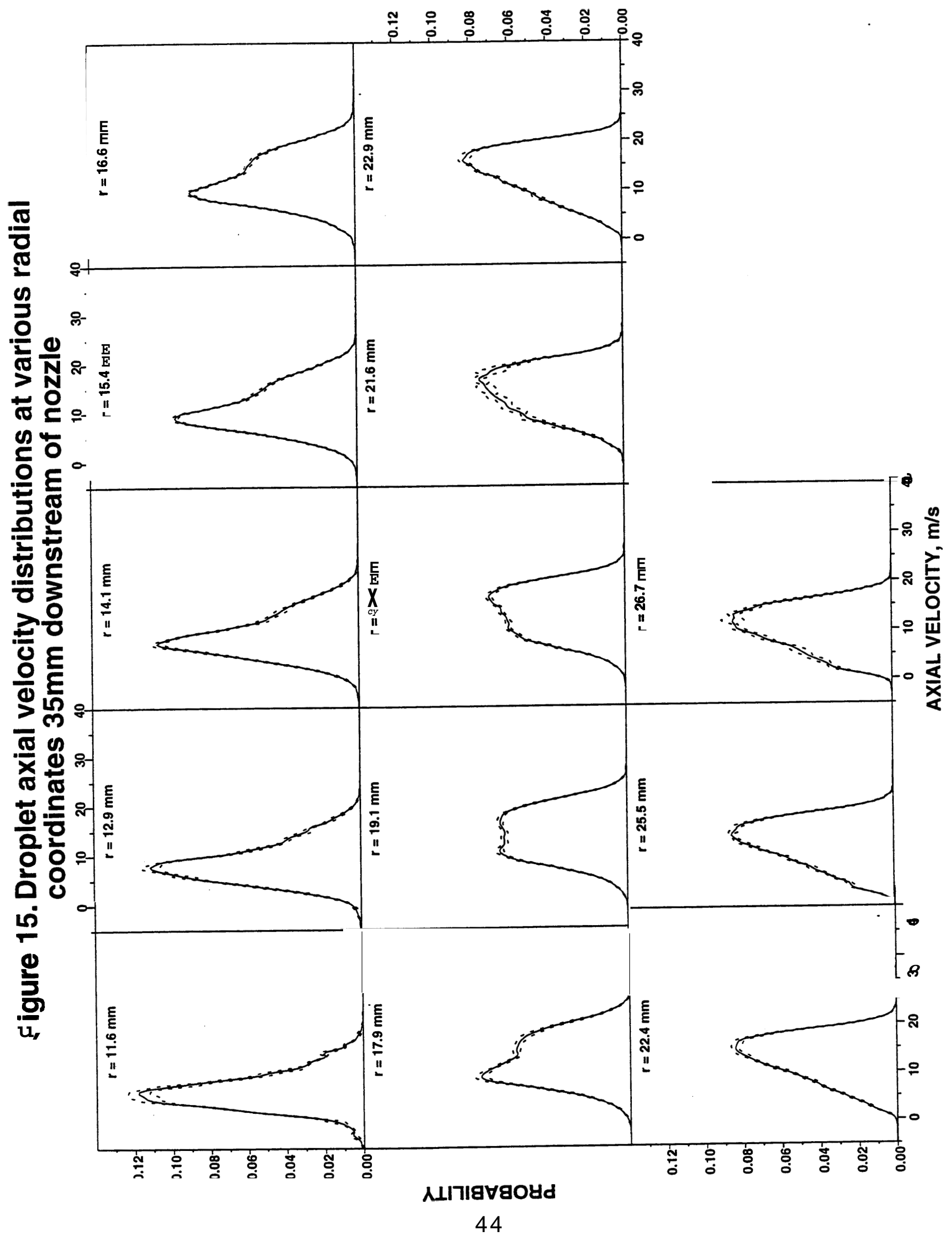




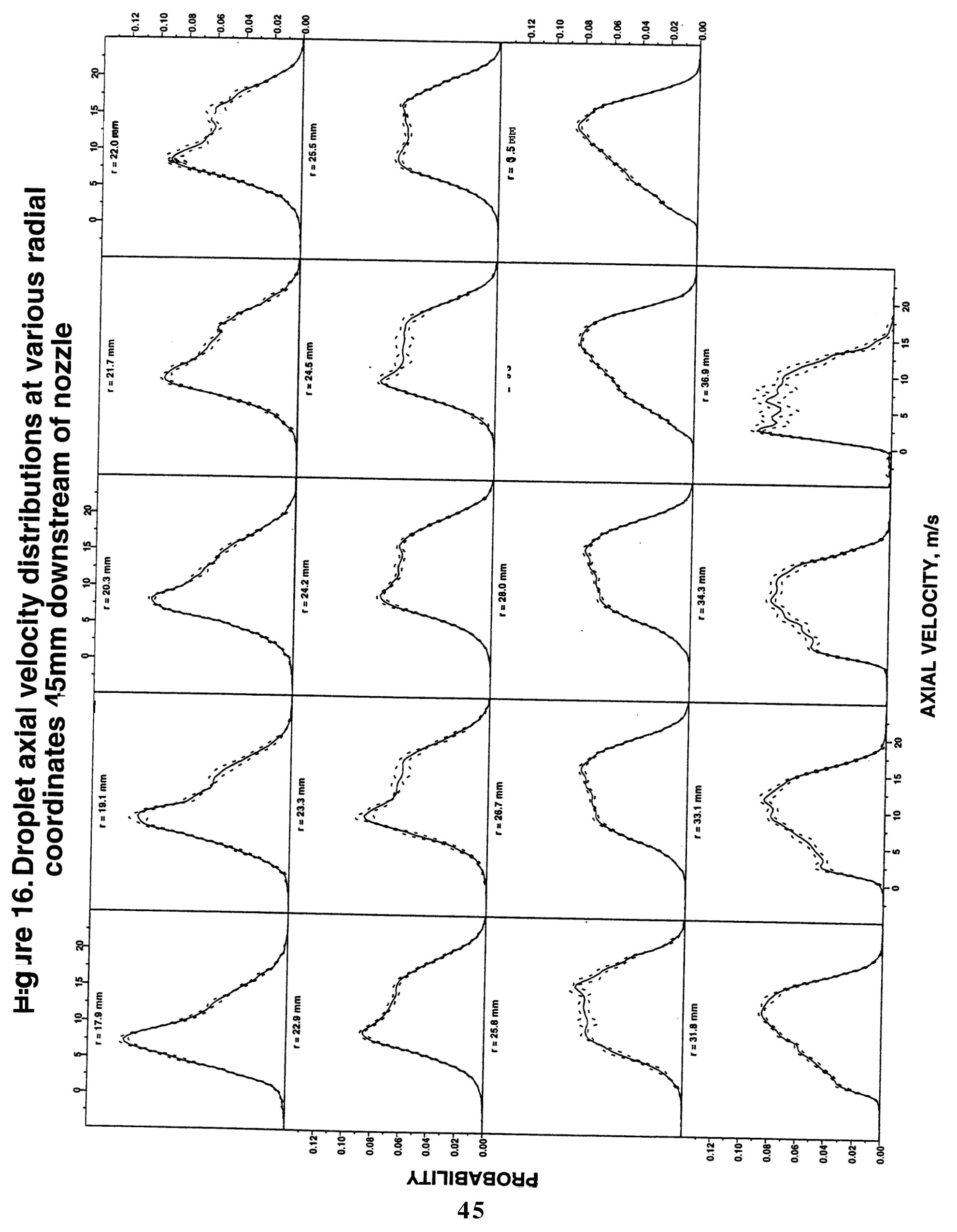




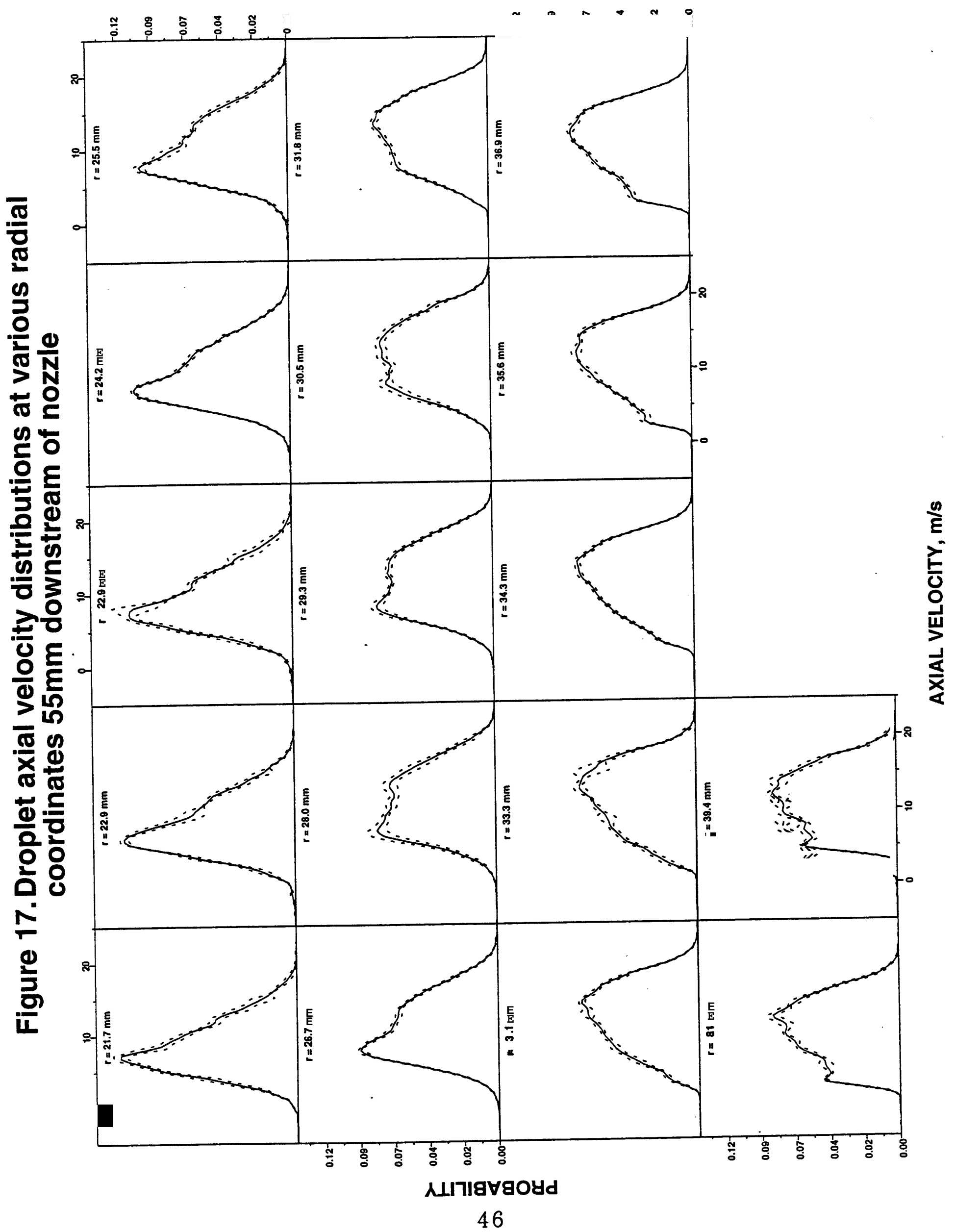




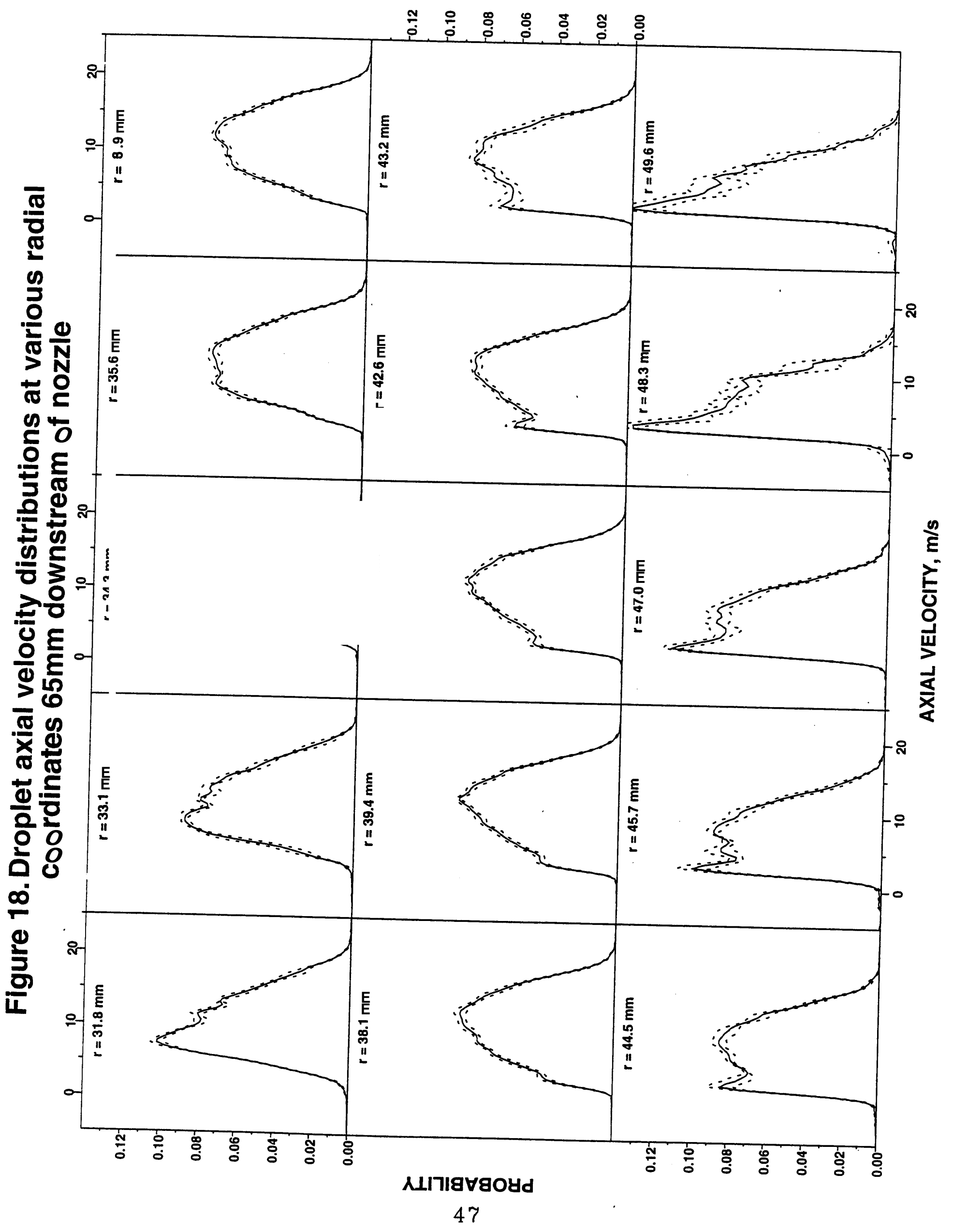




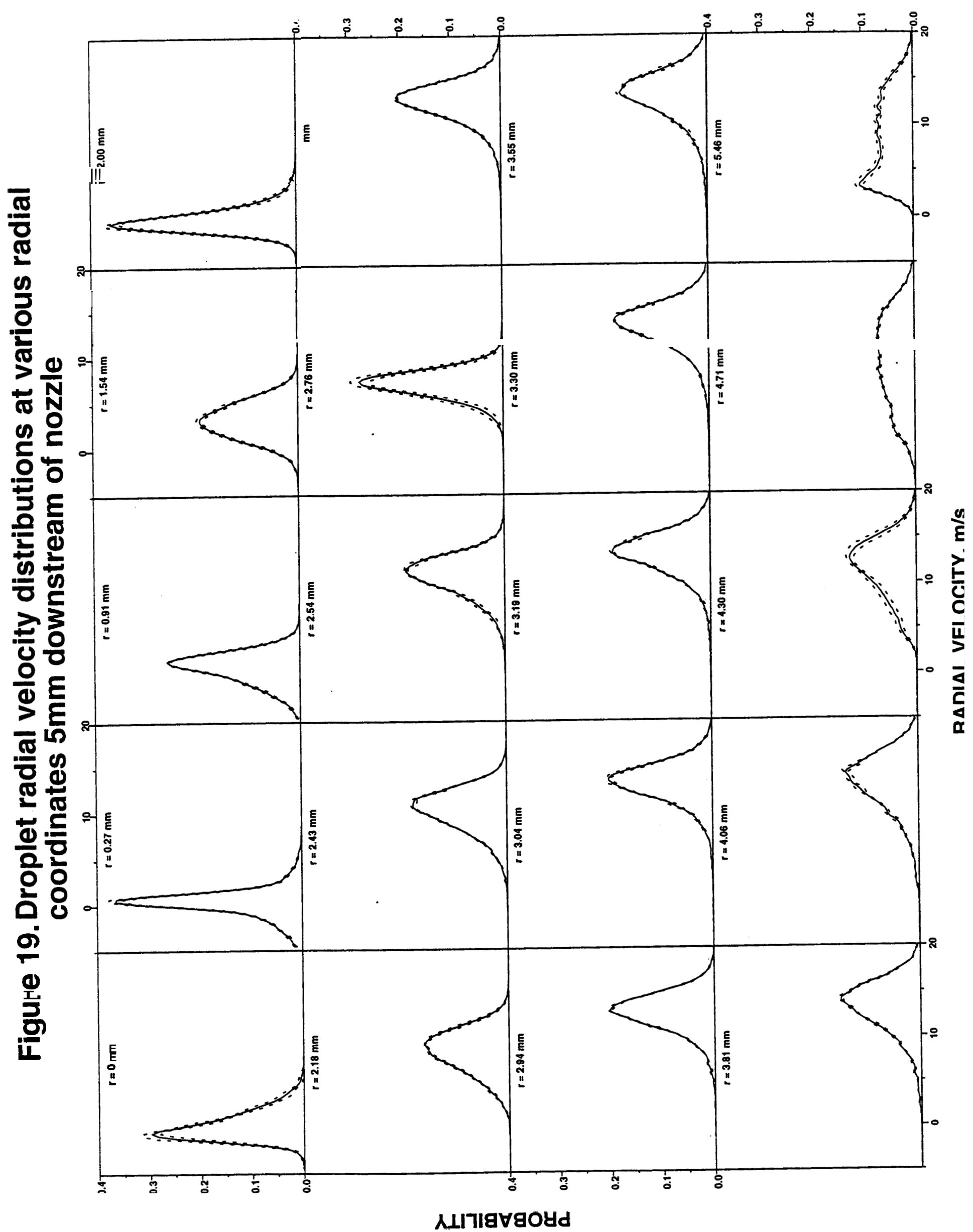




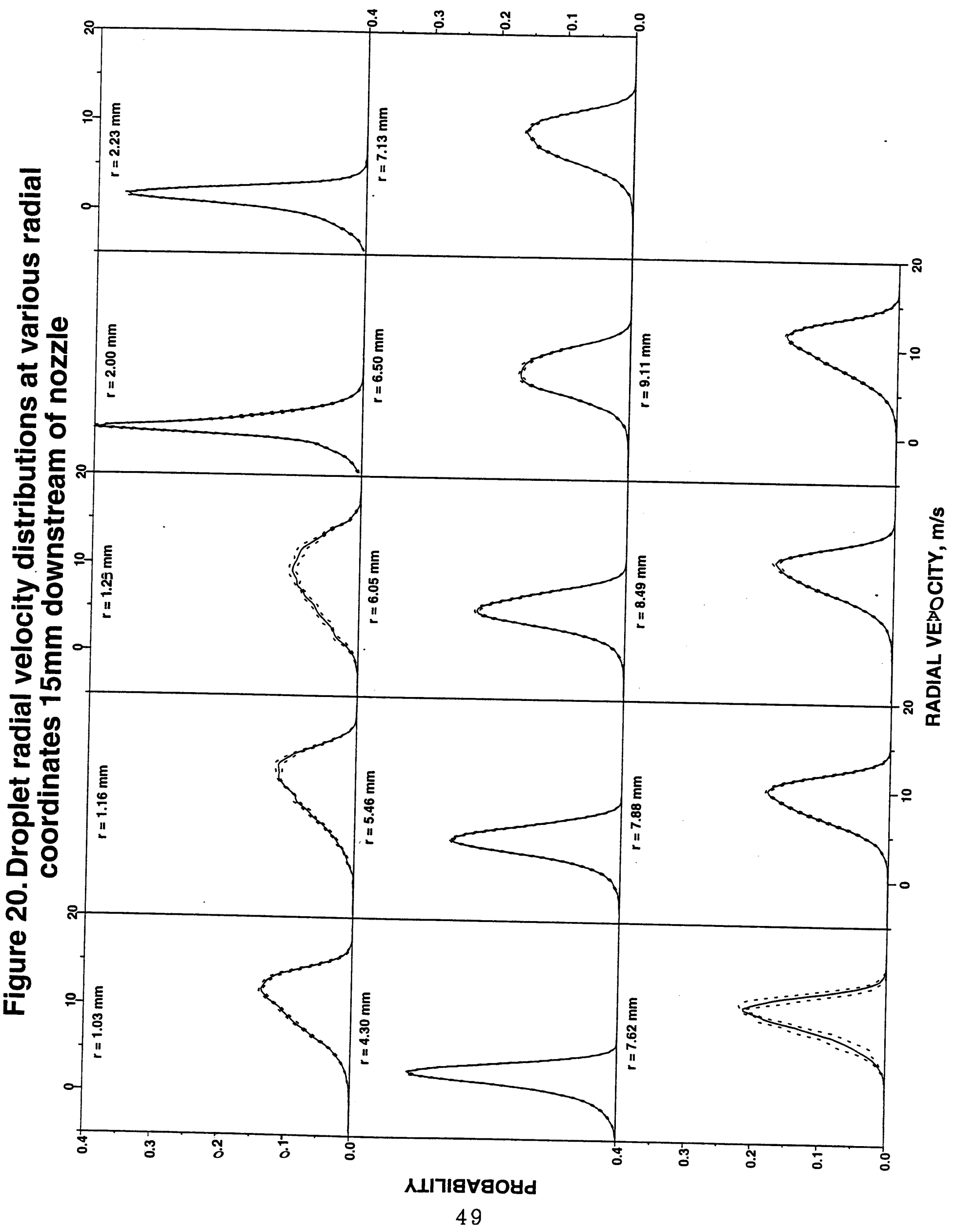




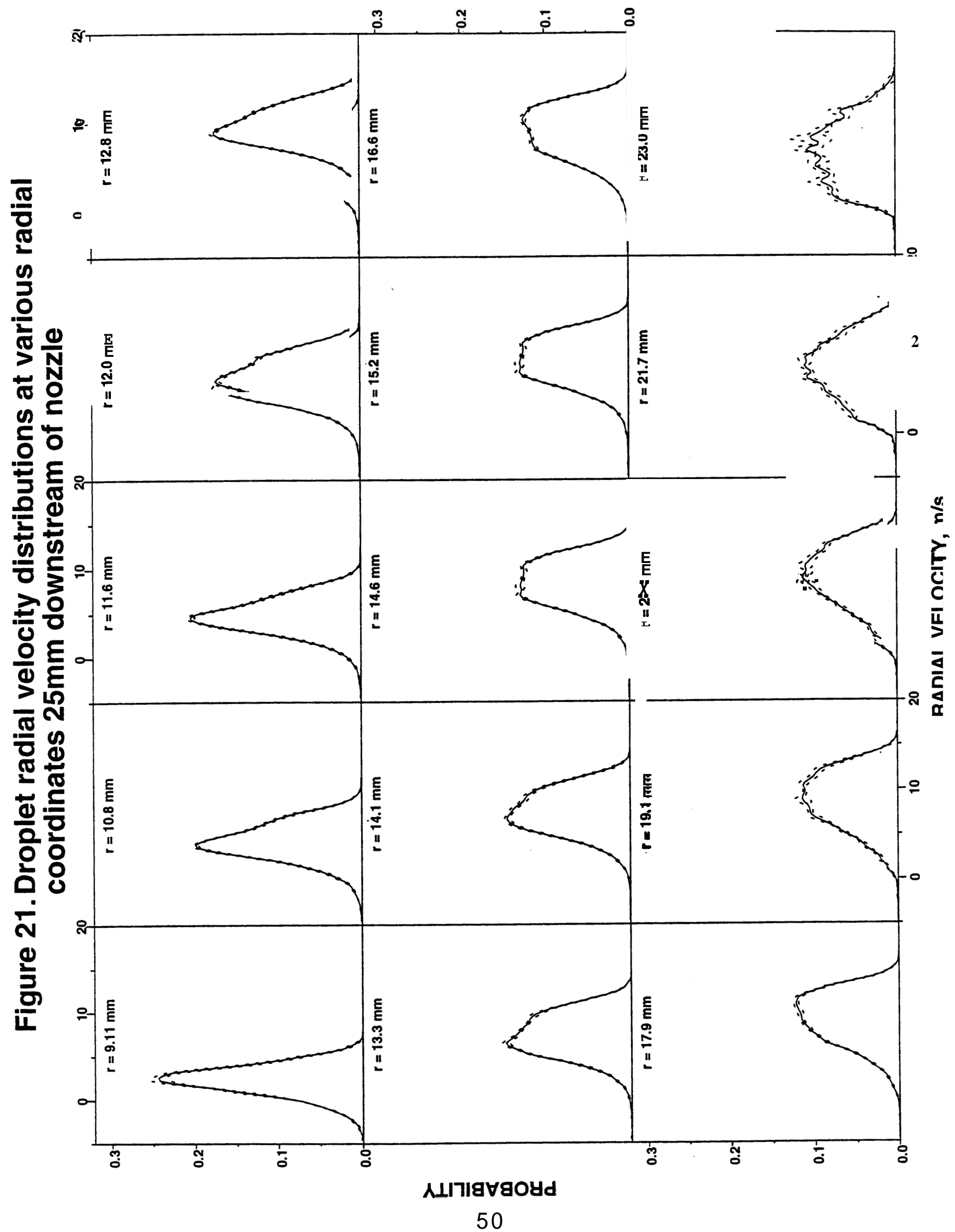




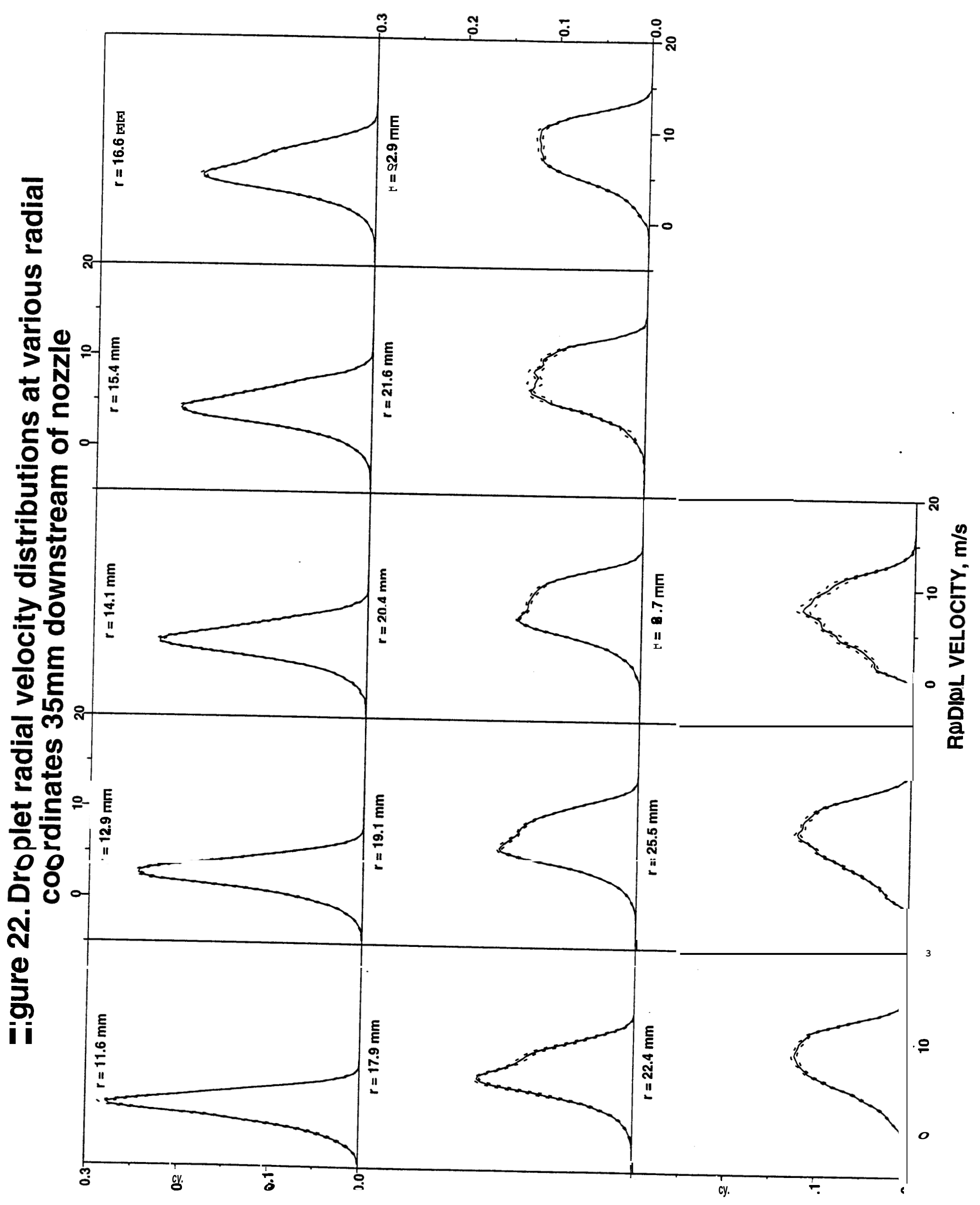




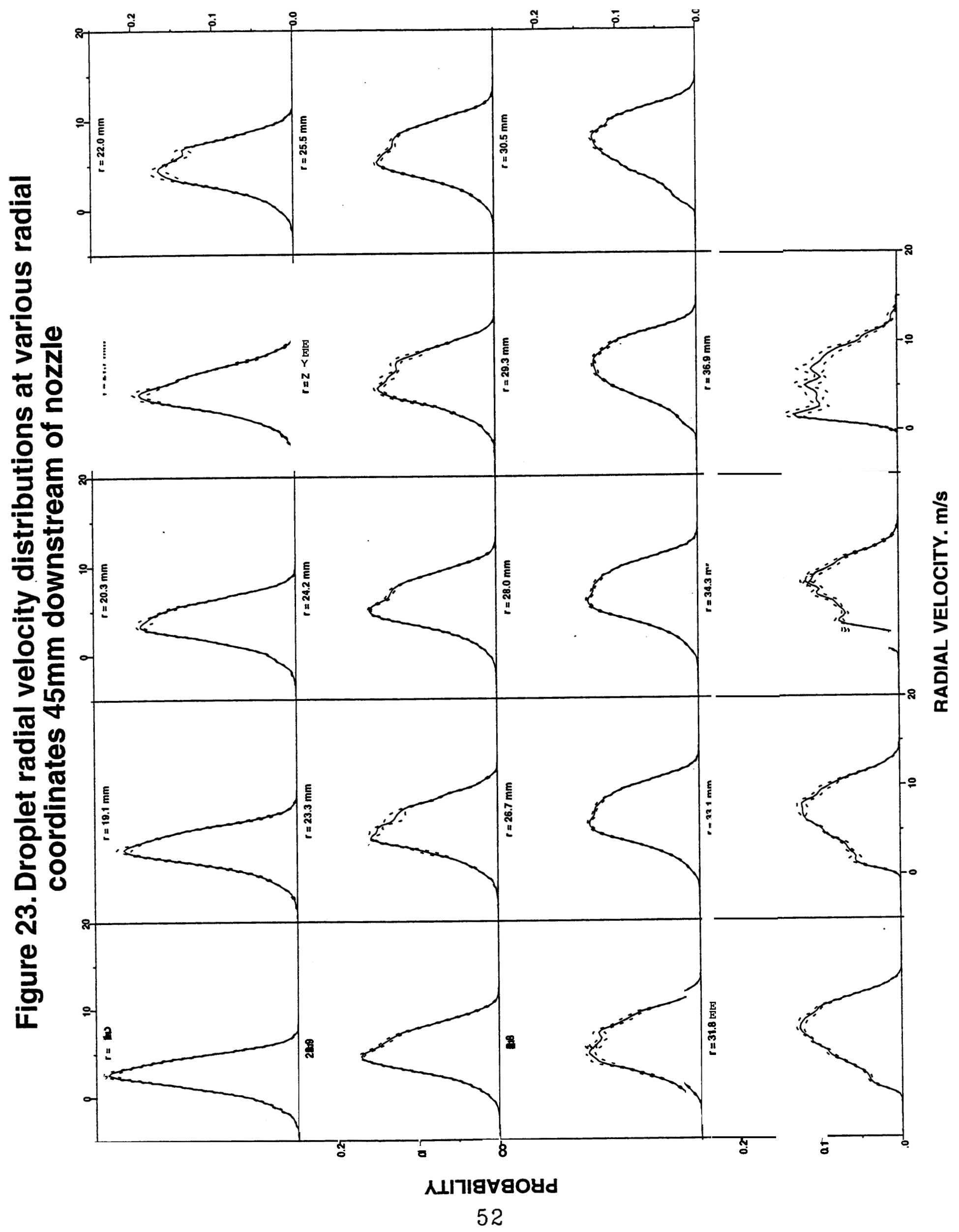




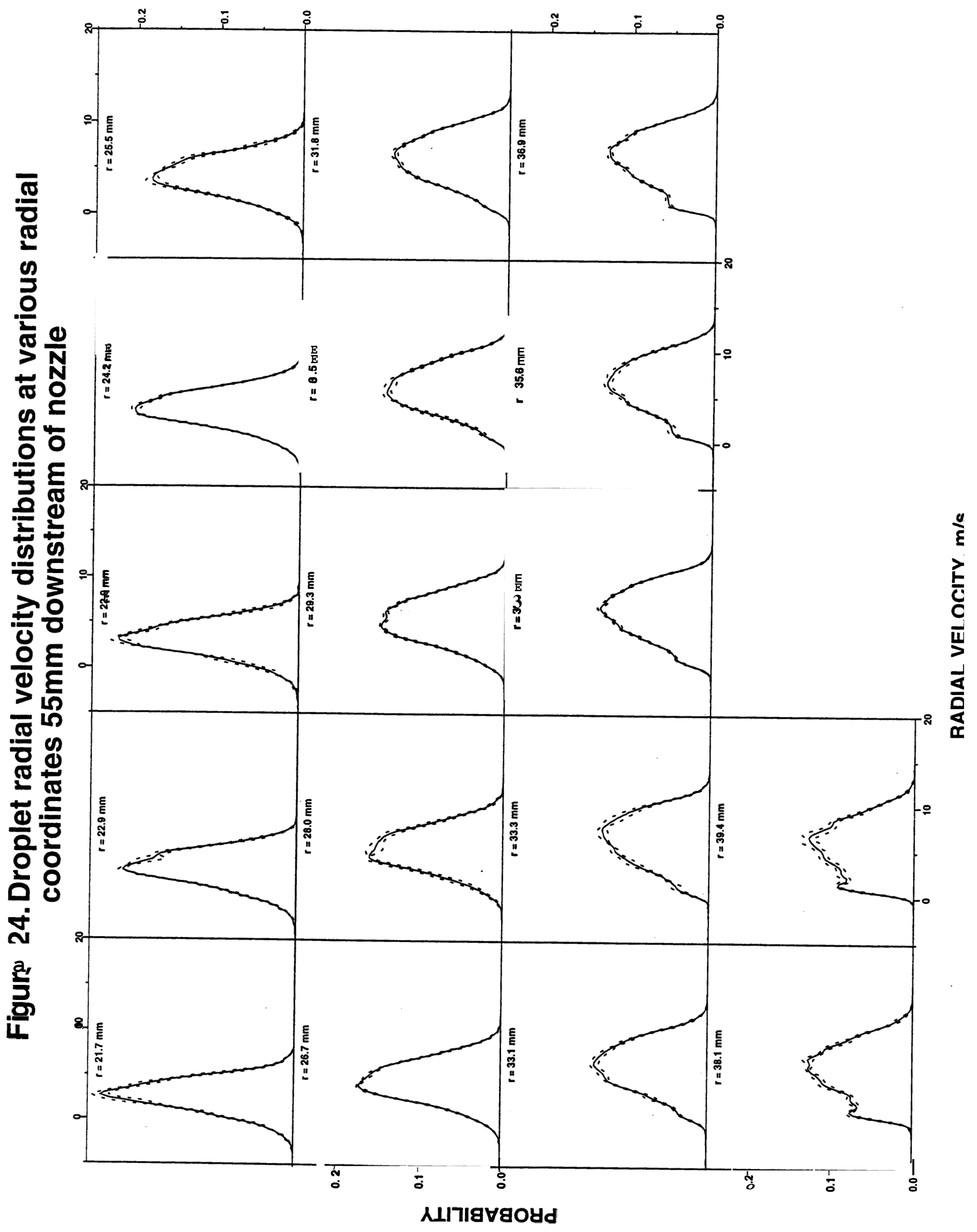




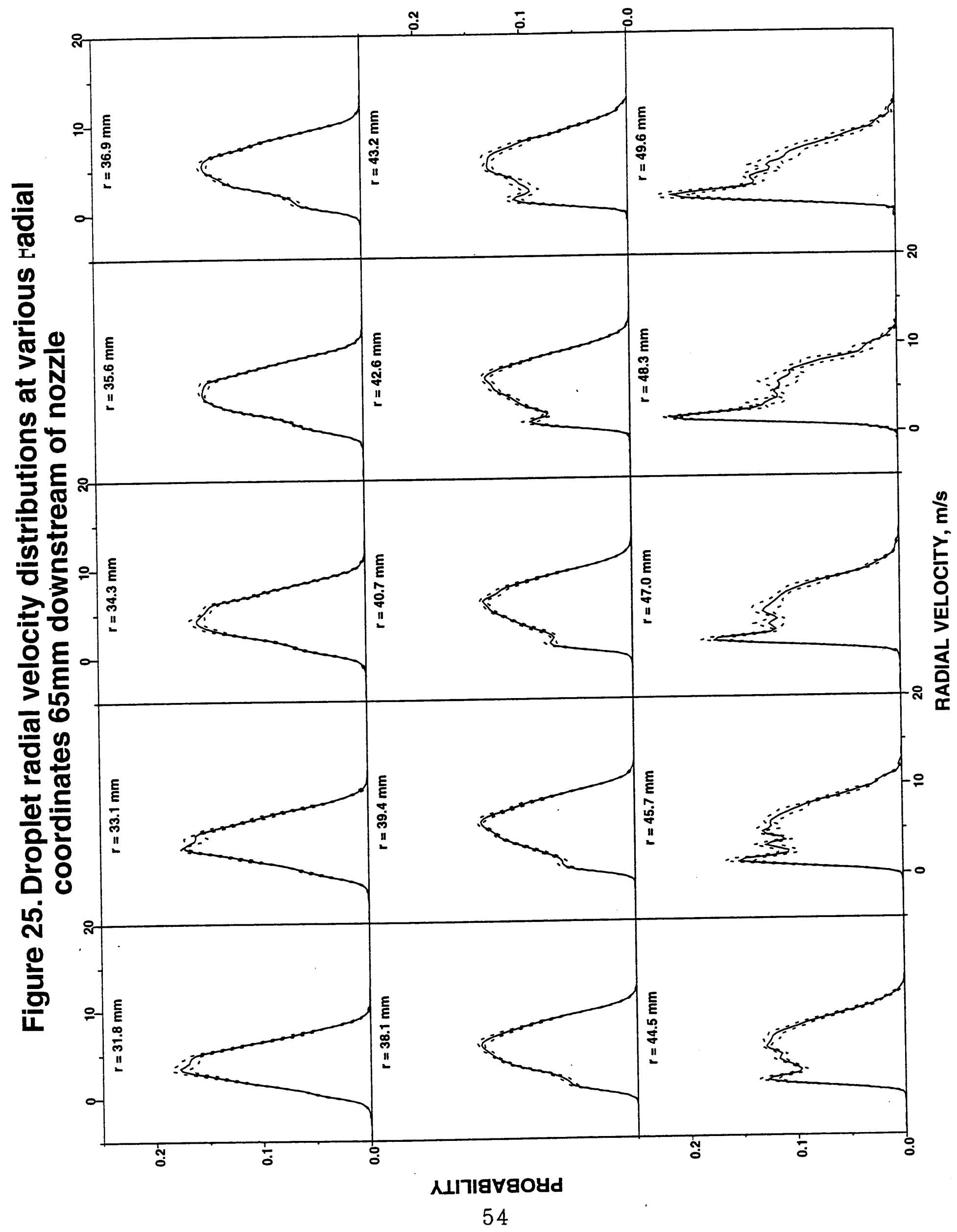


Figure 26. Sauter mean diameter, $\mathrm{D}$ at seven locations downstream of the nozzle $(z=5,15,25,35,45,55,65 \mathrm{~mm})$.
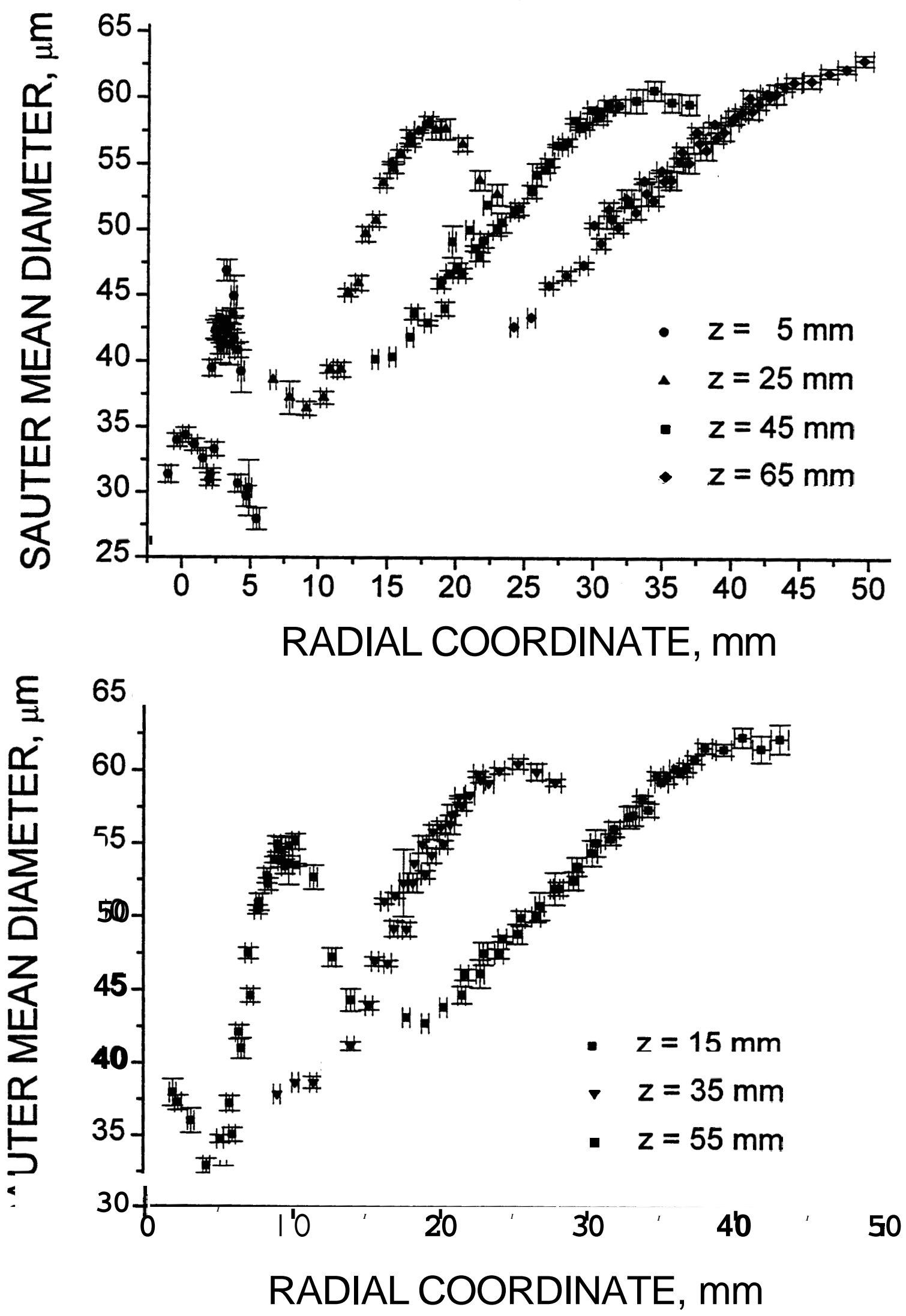

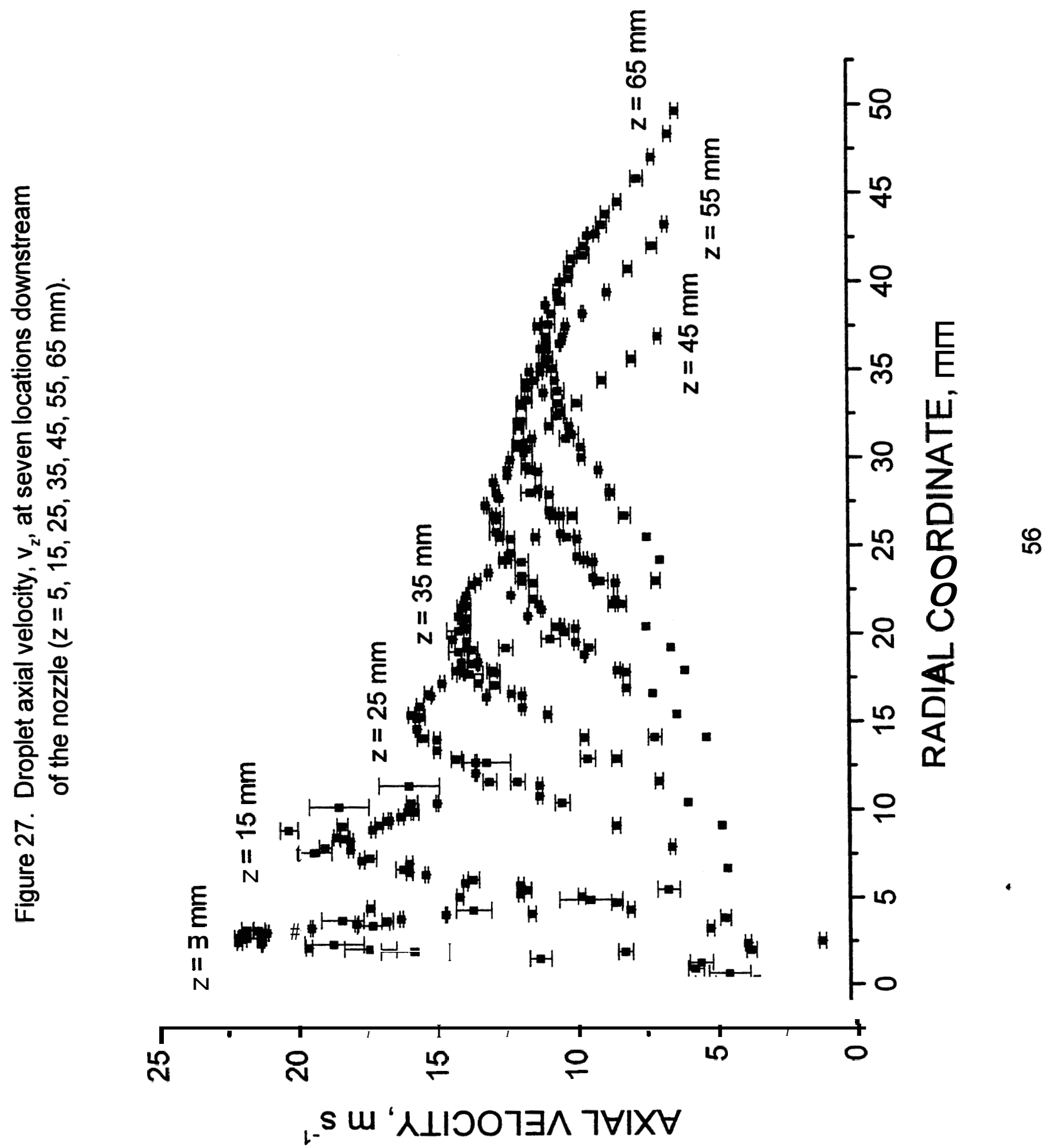

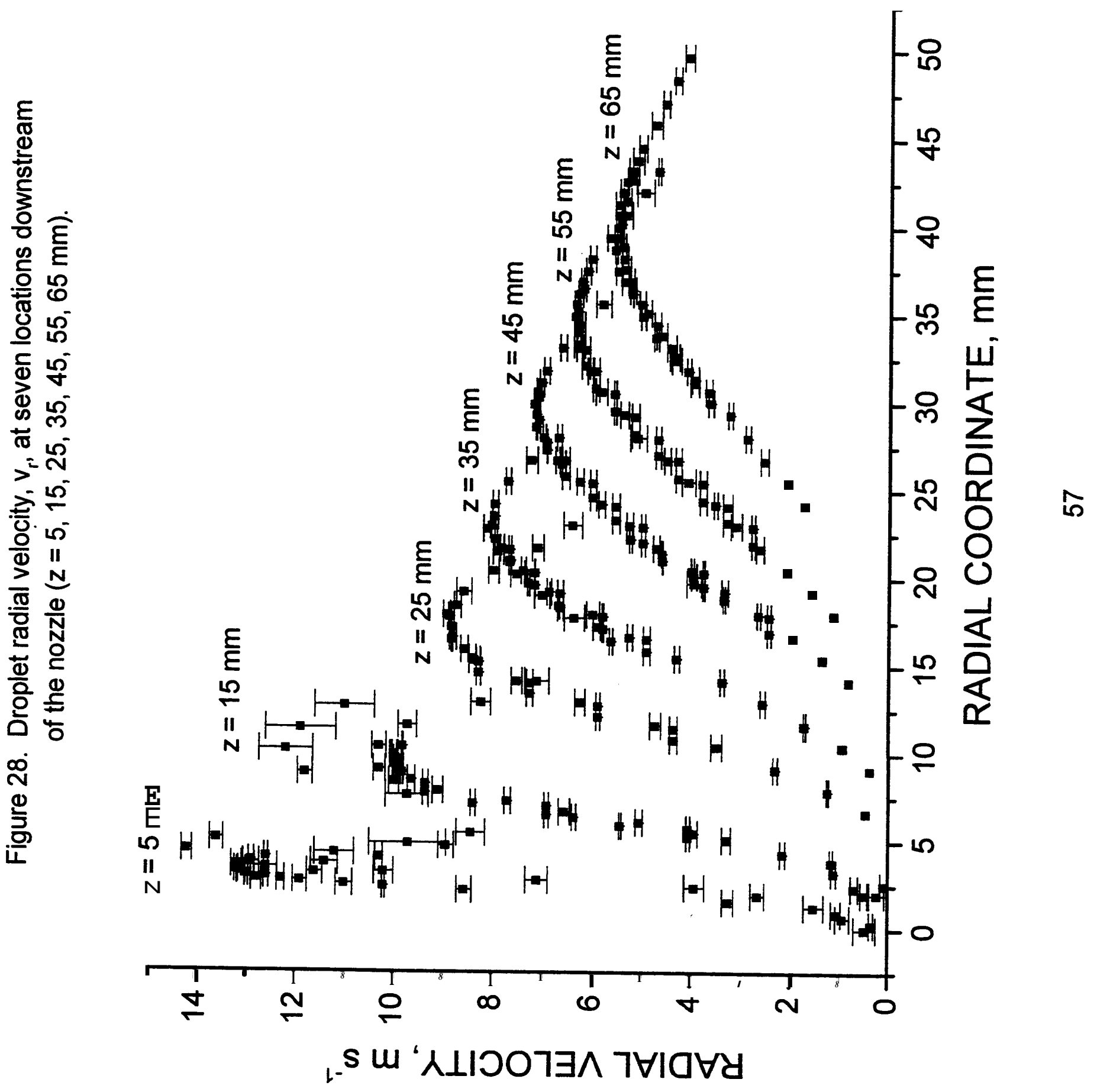
Figure 29. Droplet number densities at seven locations downstream ofthe nozzle $(z=5,15,25,35,45,55,65 \mathrm{~mm})$.
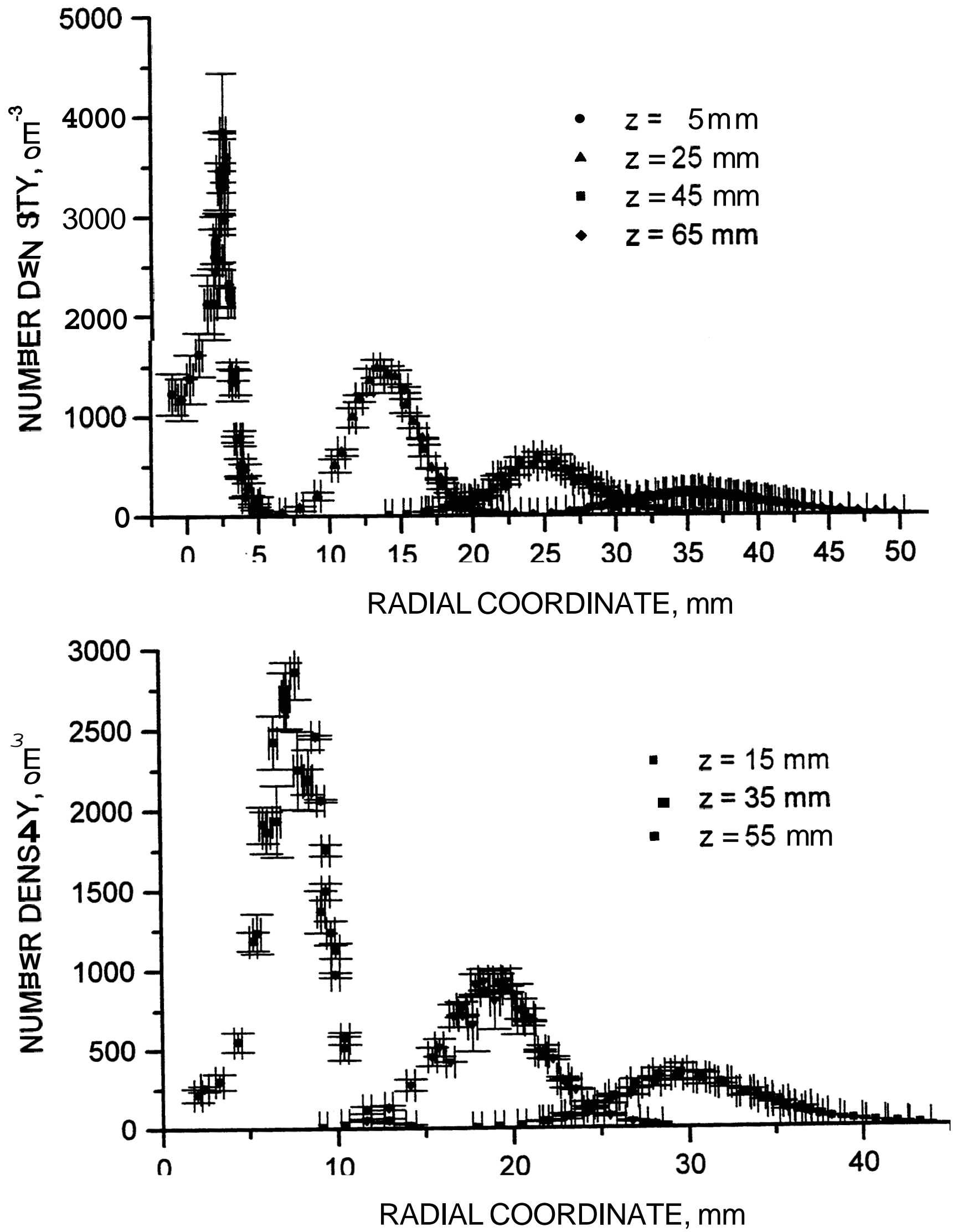
Figure 30. Droplet volume fluxes at seven locations downstream ofthe nozzle $(z=5,15,25,35,45,55,65 \mathrm{~mm})$.
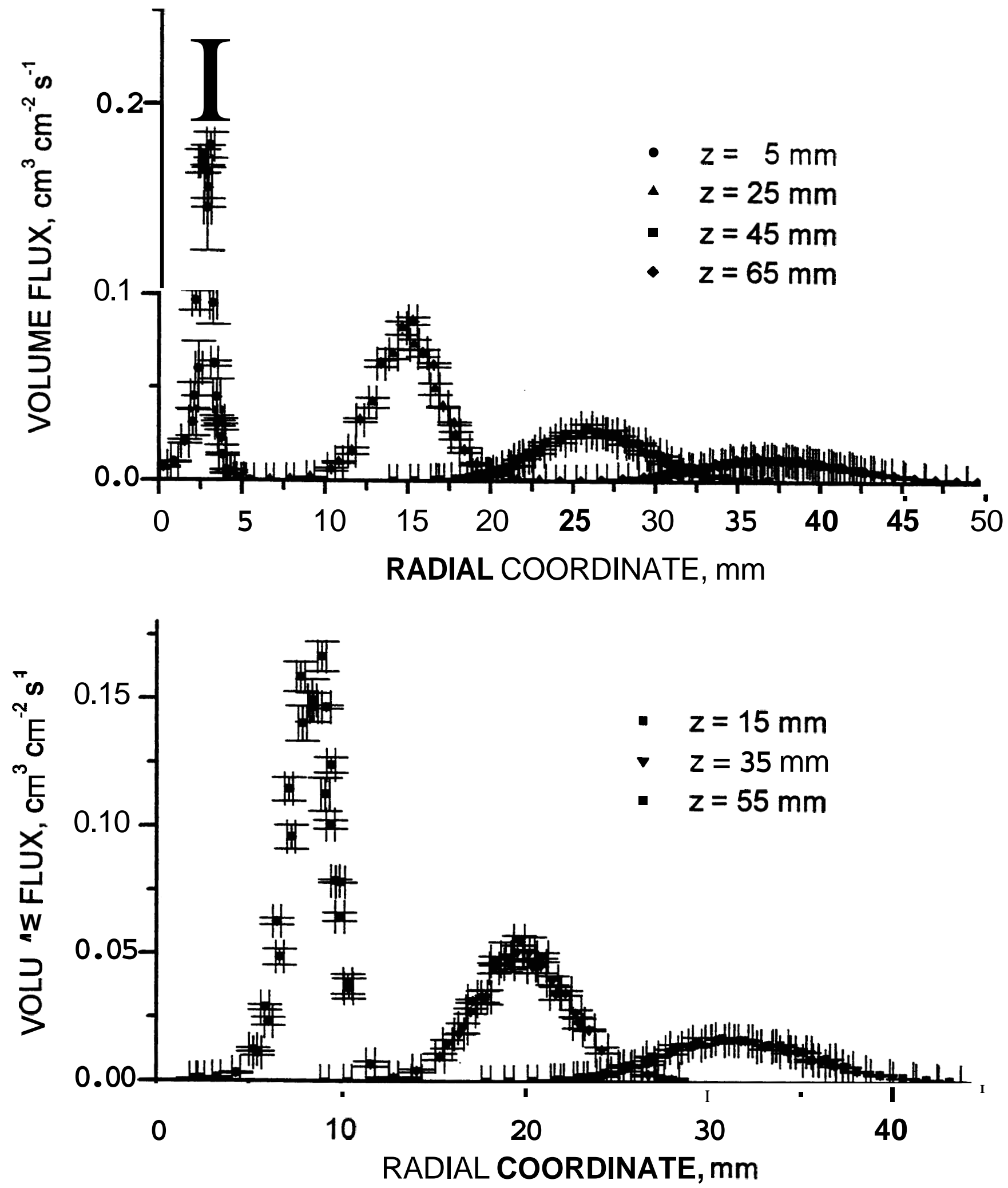
Figure 31. A comparison of reported number densities at three locations in the spray with one and two components of velocity measured.

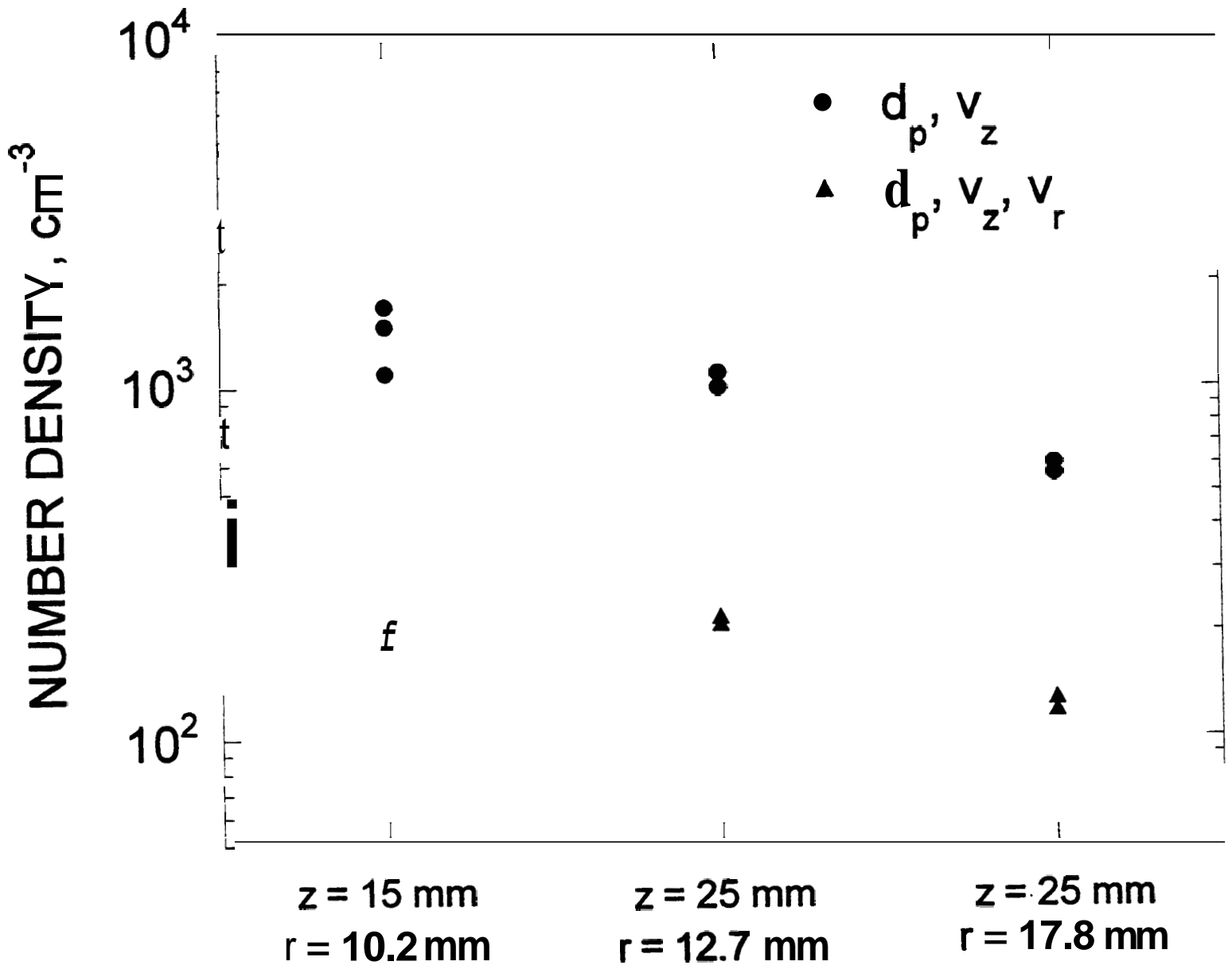


Figure 32. Comparison of reported size distributions with and without the radial component of velocity measured at (A) $\mathrm{z}=5 \mathrm{~mm}$, and

(B) $z=25 \mathrm{~mm}$.

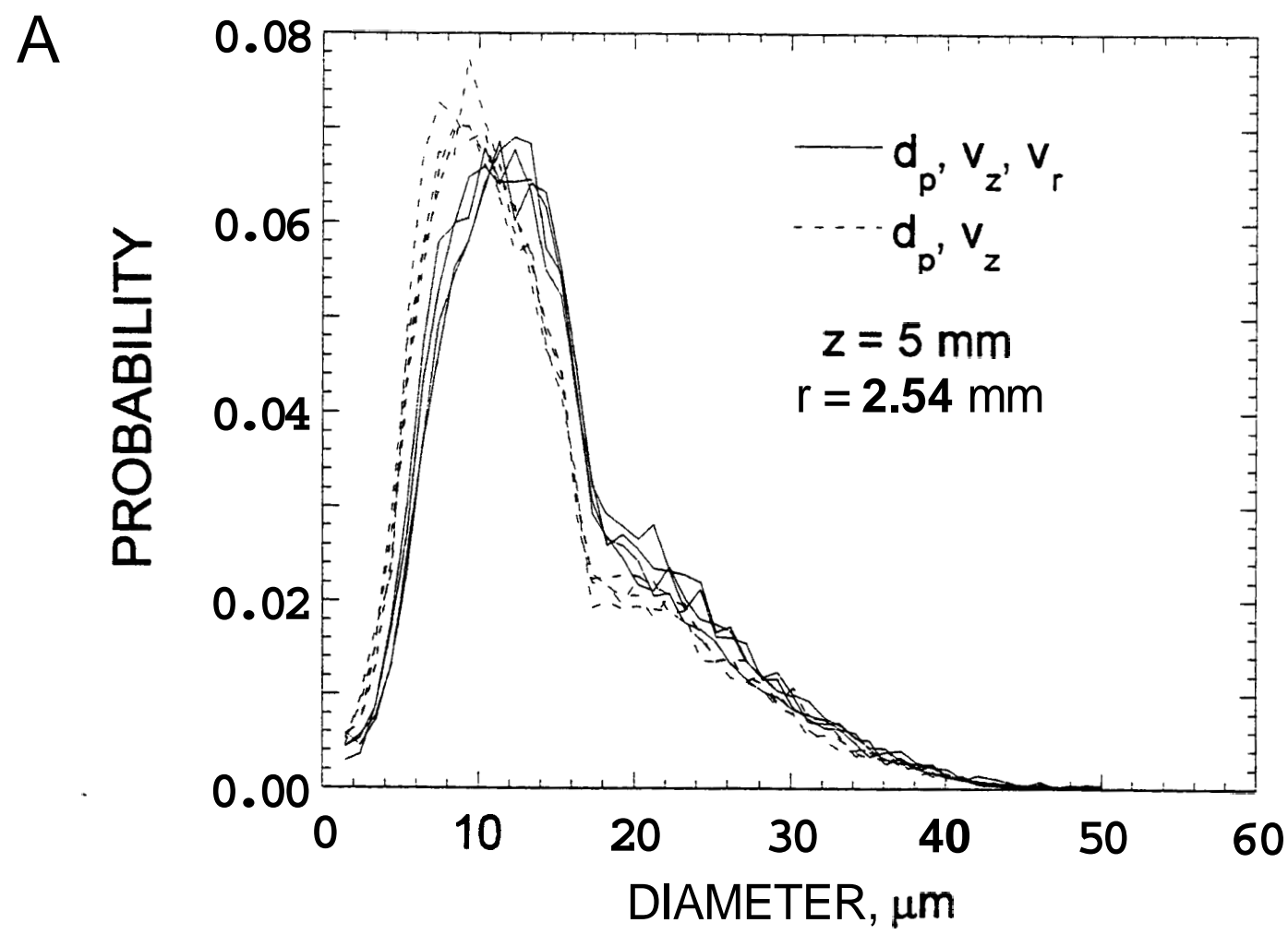

B

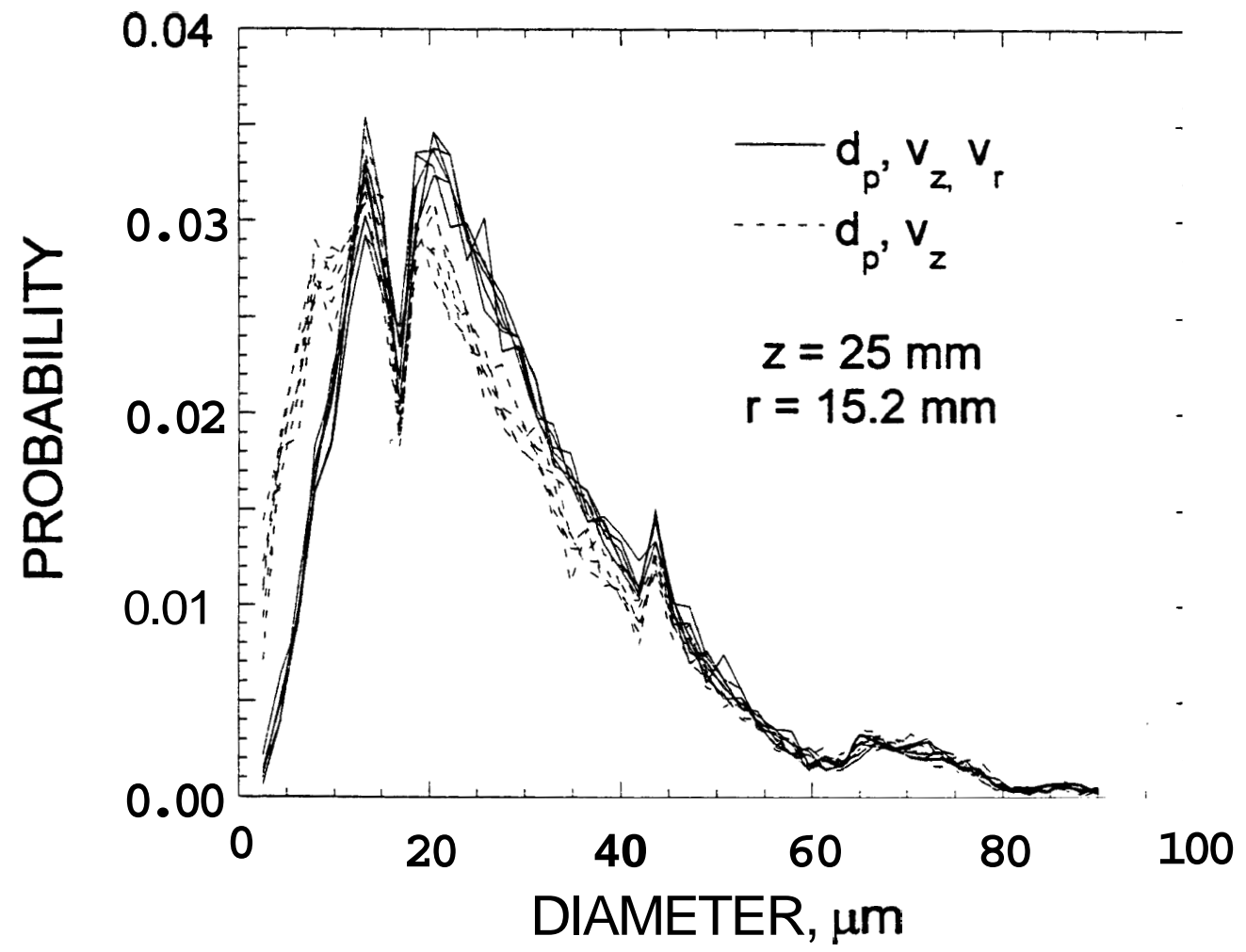


Figure 33. Raw data obtained with the PDI showing the number of fringes crossed for each measurement direction (axial and radial).

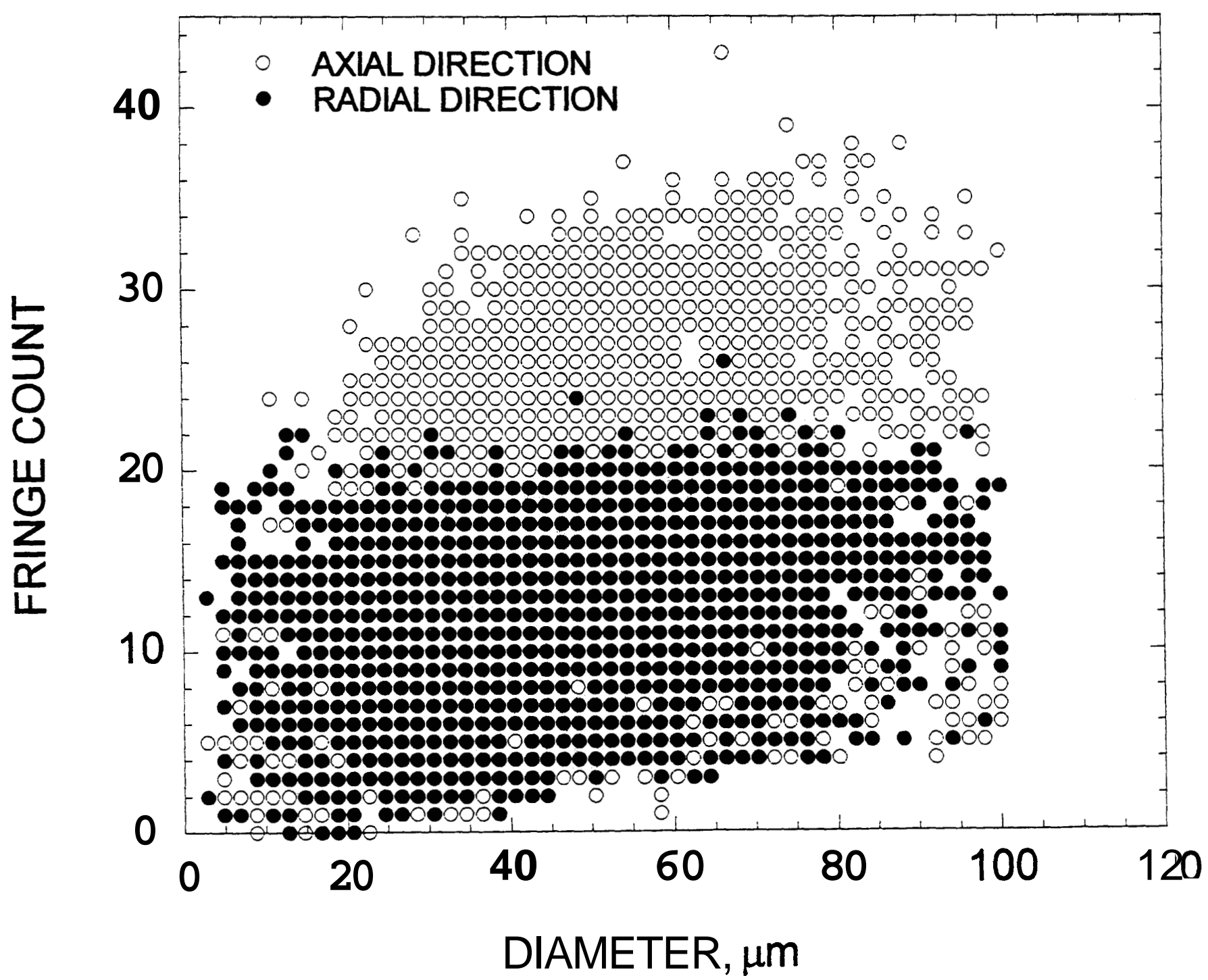


Figure 34. The calculated probe area based upon the number of fringes that individual droplets crossed.

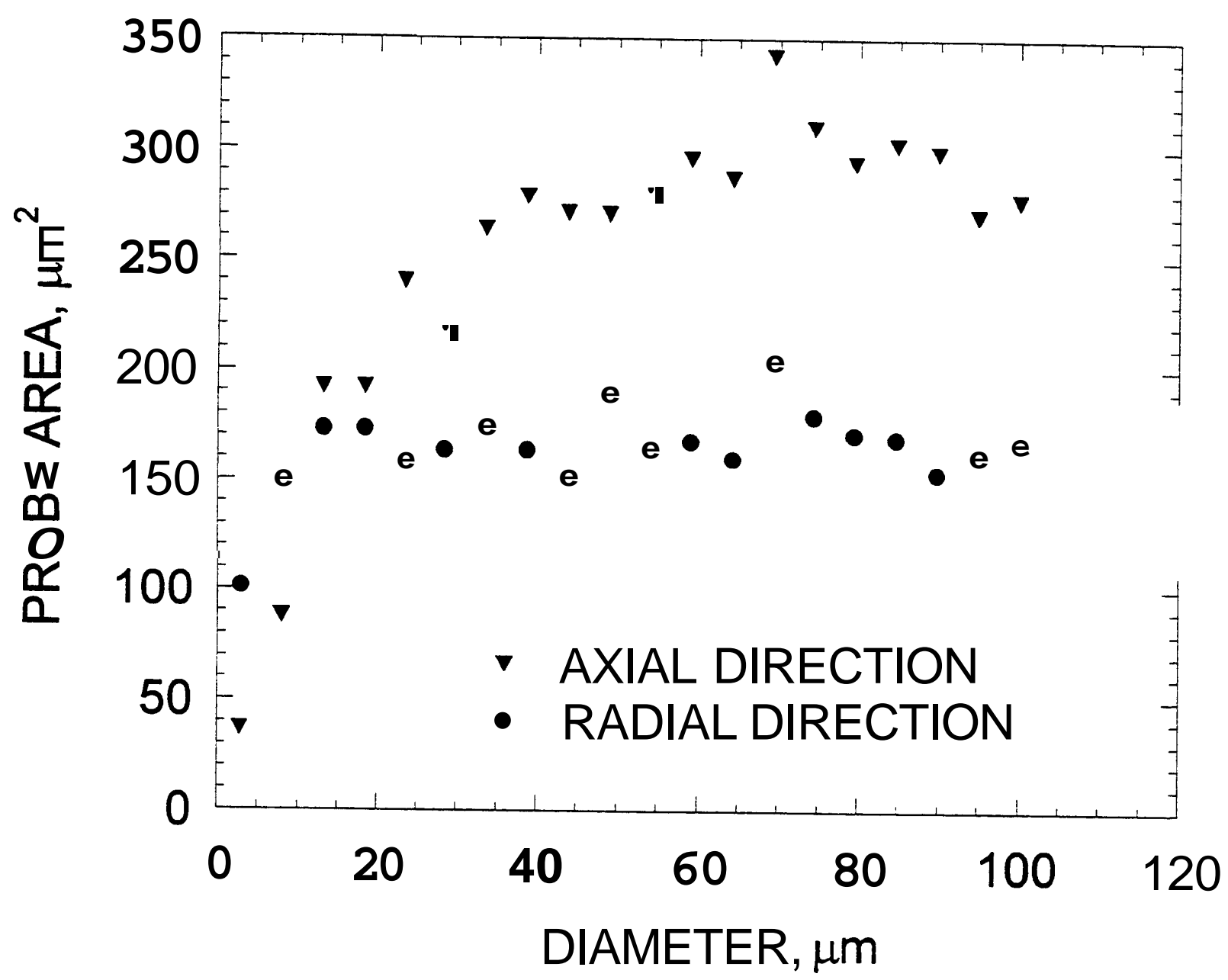


Figure 35. The normalized mass flow rate of fuel at various downstream locations. Values from the literature are shown for comparison.

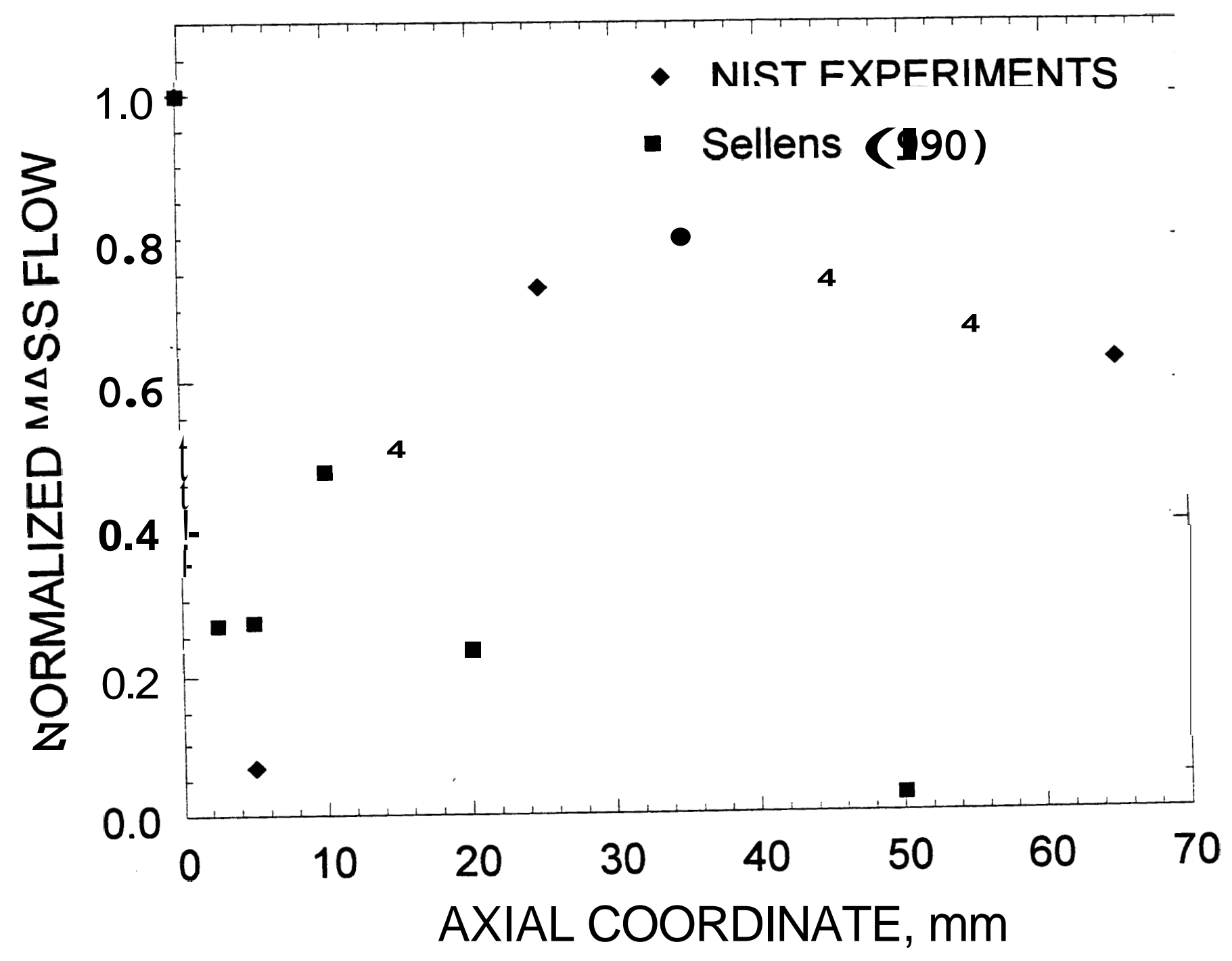


Figure 36. Number and mass distributions measured with the PDI illustrating the difficulty of measuring the number and mass distributions simultaneously.

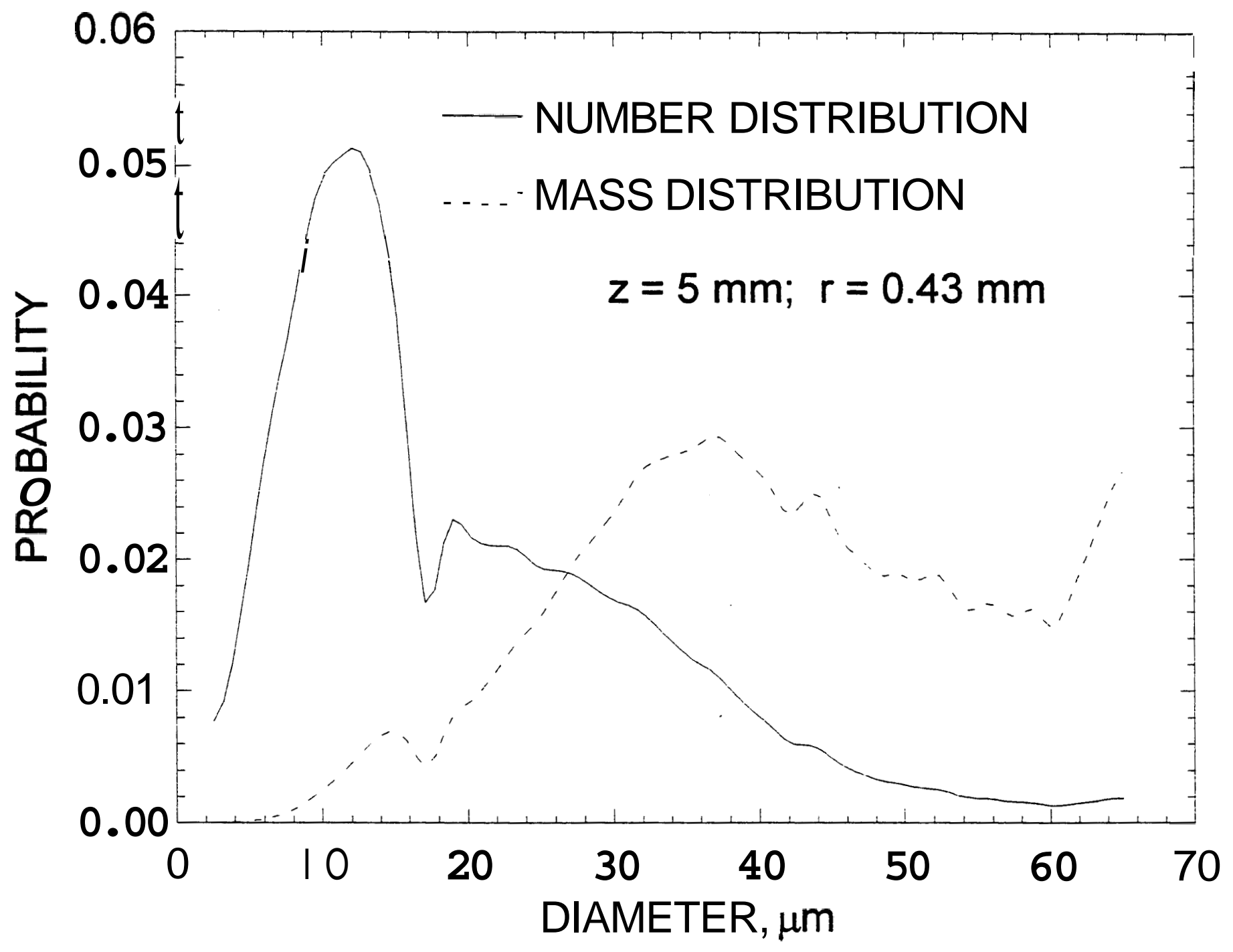


Figure 37. The exit concentrationsof various species in the reactor.

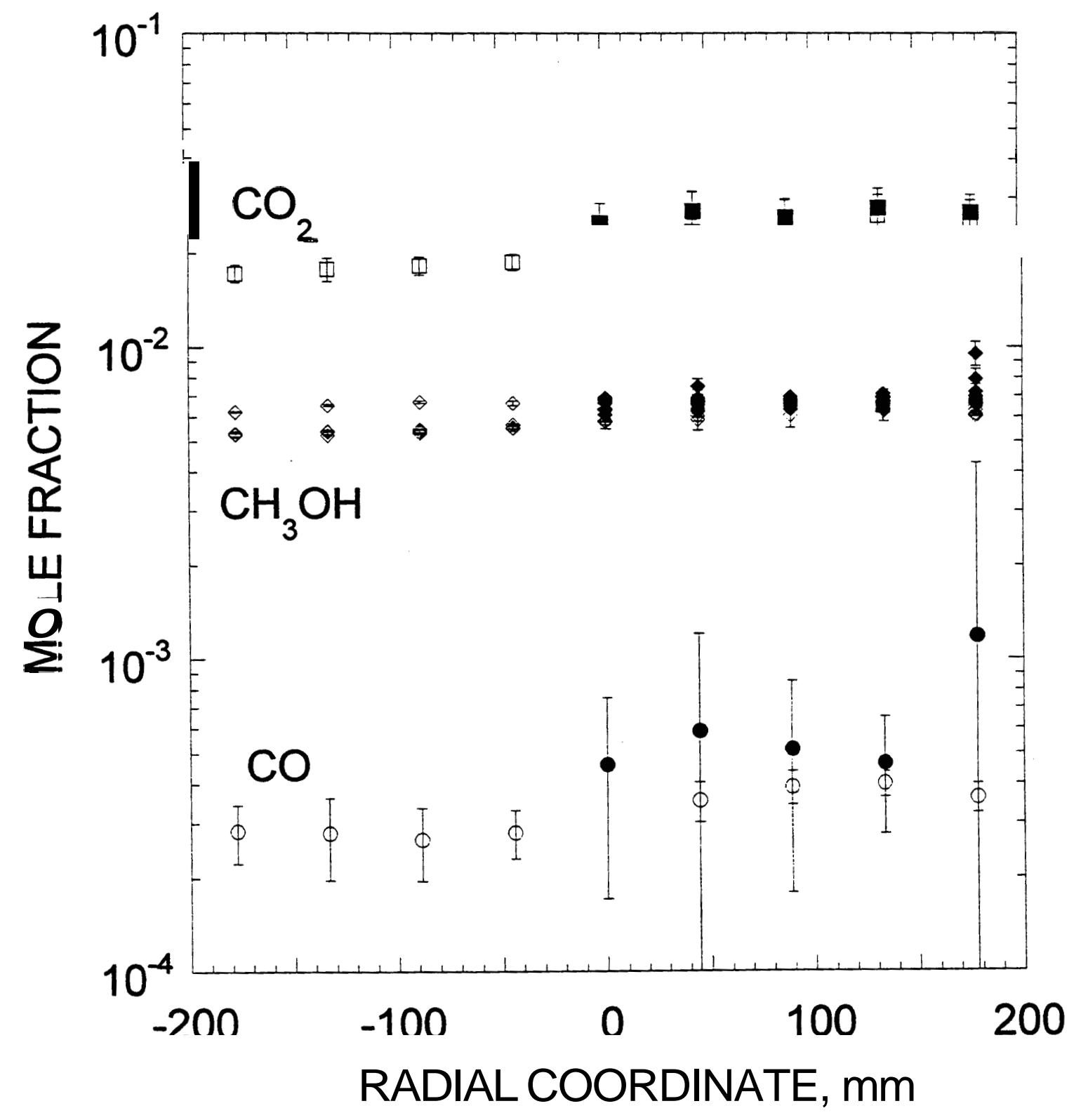


Figure 38. Theoretical species concentrations in the reactor emissions.

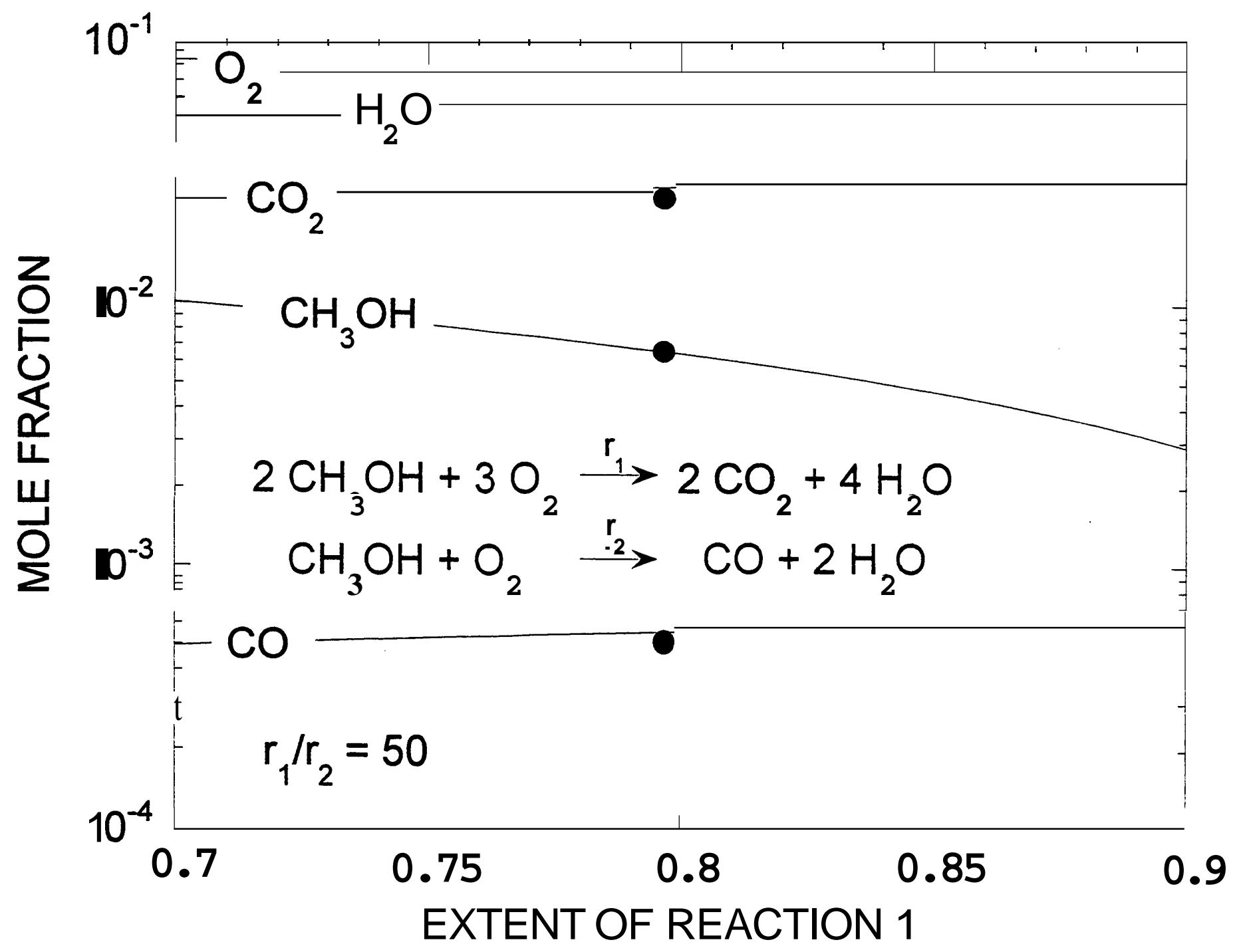


